\title{
A Solution to the Time-Dependent Stress Distribution in Suborbicular Backfilled Stope Interaction with Creeping Rock
}

\author{
Baoxu Yan $\mathbb{D}^{1},{ }^{1}$ Xingping Lai $\mathbb{D}^{1},{ }^{1}$ Hanwen Jia $\mathbb{D}^{2},{ }^{2}$ Erol Yilmaz $\mathbb{D},{ }^{3}$ and Chen Hou ${ }^{4}$ \\ ${ }^{1}$ Energy School, Xi'an University of Science and Technology, Xi'an 710054, China \\ ${ }^{2}$ Deep Mining Laboratory, Shandong Gold Group Co., Ltd., Yantai 264000, China \\ ${ }^{3}$ Department of Civil Engineering, Geotechnical Division, Recep Tayyip Erdogan University, Fener, Rize TR53100, Turkey \\ ${ }^{4}$ Center for Rock Instability and Seismicity Research, School of Resource and Civil Engineering, Northeastern University, \\ Shenyang 110819, China
}

Correspondence should be addressed to Hanwen Jia; jiahanwen@sd-gold.com and Erol Yilmaz; erol.yilmaz@erdogan.edu.tr

Received 9 February 2021; Revised 20 February 2021; Accepted 9 March 2021; Published 23 March 2021

Academic Editor: Lijie Guo

Copyright (C) 2021 Baoxu Yan et al. This is an open access article distributed under the Creative Commons Attribution License, which permits unrestricted use, distribution, and reproduction in any medium, provided the original work is properly cited.

\begin{abstract}
The creep behavior of deep weak rock masses is important due to an underground opening. Appreciating the nature and source of these deformations requires the knowledge of rock mass and ground support interaction. The theoretical solution of the backfill's internal stresses needs to consider the time-dependent effect. In the present study, the coupling interaction between the creep behavior of the nearby rock material and the internal stresses in the backfilled stope is considered and the interaction characteristics are given analytically. A solution is then proposed regarding the time-dependent stress distribution in suborbicular backfilled stope interaction with creeping rock. Besides, the correctness of the theoretical solution is verified by numerical simulation, while influential parameters such as stope buried depth, lateral pressure coefficient, horizontal stress ratio, creep time of surrounding rock mass, delay time of the backfill, and Young's modulus are thoroughly discussed. Research shows that when the stope buried depth becomes large as well as the rheological effect of the nearby rock materials becomes significant, the stress distribution in the backfill material exceeds its self-weight stress and presents significant time-dependent characteristics. The delayed backfilling weakens the backfill's ground support effect on the nearby rock material. Hence, timely and multipoint simultaneous backfilling is needed for a stope with significant rheological deformation of surrounding rock mass. Lastly, this work will offer useful knowledge while designing the backfill materials for underground mines.
\end{abstract}

\section{Introduction}

How to dispose of the mined stope and large number of tailings produced in the mining sector is the current research hotspot [1]. The main aspects of tailings disposal are the use of tailings for construction material [2-4] to absorb carbon dioxide in the atmosphere, to mitigate the greenhouse effect [5], to store tailings on surface disposal areas [6], and prepare them in the cemented fill form to fill the underground mined-out stopes [7]. Among them, the preparation of tailings as cemented mine fill into underground openings is not only beneficial to the environment, regional animal, and plant protection [8] but also can reduce the mining process of ore loss depletion and heavy metal emissions. The mine fill method used can bring significant economic benefits to mines and solve the problem of mining-induced massive surface subsidence, which can be called "One waste management solving two disasters" [9].

However, the backfill mining process also faces new problems, such as how to effectively coordinate the strength requirements with the backfilling cost to achieve maximum economic benefits $[10,11]$, how to control the barricades destabilization disaster $[12,13]$, the self-supporting stability of the backfilling mass [14-16], and how to ensure the stability of the backfilling mass as an artificial pillar or sill pillar $[17,18]$. The core issue is the interaction mechanism between mine backfilling and the nearby rock materials $[19,20]$. The stress distribution within the backfill and its time dependence should not be neglected since there are significant multiphysical field and time effects in the 
settlement, drainage, consolidation, strength acquisition, and microstructure evolution of the backfill after it is filled into the mined-out stopes [21].

With the depletion of shallow resources, more and more mines are moving towards deeper mining. The surrounding rock mass under the influence of high temperatures and high stresses at depth will show significant rheological effects [22], which are quite different from the deformations of shallow nearby rock materials; the stress redistribution around the nearby rock material under the influence of mining activities is not instantaneous but rather a gradual development over time $[23,24]$. The aging of deformation resulting from this progressive development is likely to occur in weak [25] or jointed rock mass $[26,27]$ under the effect of high ground stresses. Thus, the effect of the development of deformation on the internal stress distribution of backfilling is not instantaneous but rather a gradual evolution of the nearby rock material under the effects of excavation sequence, large stresses, and temperature conditions [28, 29].

Theoretical analyses can provide a preliminary and rapid estimation of the stress distribution inside the backfill, which is very useful for the initial assessment of filling capacity and options [30, 31]. Until now, numerous works have been undertaken on the internal stress distribution of the backfill, including two- and three-dimensional analytical solutions for the backfilled stope's internal stresses, taking into account the shape and inclination of the stope [19, 32-39] and the saturated conditions of filling [33]. However, the effect of time-dependent deformation of rock on the backfill has been neglected so far. This is usually reasonable in shallow stope or in places where the creep behavior of the nearby rock material is not apparent [40]. However, for deep, high stress and temperature rock mass, many studies show that the rock' creep behavior is significant, and the stress distribution in the backfill will be largely affected by creeping rock mass [18]. This phenomenon is also seen in the field monitoring with regard to the time-dependent stress distribution in the backfill. Unfortunately, no research results regarding analytical solutions have been published to solve the problem of the backfill's time-dependent stress distribution.

In this study, the creep behavior of the mechanism between mine filling and the nearby rock material was analyzed. The theoretical solution of the interaction between the circular roadway and the filling mass was also established while a solution to the time-dependent stress distribution in suborbicular backfilled stope interaction with creeping rock was given. The accuracy of the solution is verified by the numerical simulation. Finally, the geometry and depth of the backfilled stopes and their geo-stress conditions were also analyzed while discussing the changes in the backfill's internal stresses.

\section{Interactions between Rock and Backfill}

Immediately after the formation of stope, elastic or elastoplastic behavior of the nearby rock material occurs, which is generally considered to be time-independent and can be accomplished in a very short period of time [41]. It generally takes some time for the backfill to fill the stope, depending on the filling capacity and the size of the stope. After the backfill placement into mined-out voids, it needs some time to harden [42]. Thus, it tends to lag behind the elastic or plastic deformation of the surrounding rock material [22]. However, the nearby rock material continues to undergo significant rheological effects due to the stresses in the surrounding rock, and the deformation converges to stope [17]. The deformation is time-sensitive. After filling the stope, the backfill material can be considered as a passive support structure without the ability to generate active support for the nearby rock material. The magnitude of the backfill's ground support is limited by the ability of the nearby rock material to squeeze the backfill. The support reaction force generated by backfilling is passive in nature; only when the nearby rock material deforms and squeezes the backfilling, the backfill will produce some support reaction force on the nearby rock material, and the effect of this support reaction force is affected by the size and nature of the mining space [43]. The support reaction of the backfill on rock will affect the development of creep (time-dependent) deformation of the nearby rock material. Thus, the interaction between mine fill and the nearby rock material has a temporal and spatial coupling effect.

Figure 1 displays the time-dependent interface between creeping rock and filling material. It is considered that the temporal deformation that occurs after the completion of excavation is mainly the creep behavior of the nearby rock material influenced by geo-stress. The expansion and shrinkage deformation can occur when cementitious backfill is affected by drainage, consolidation, and cementation hydration processes, and this process is time-dependent, as confirmed by the results of previous research $[44,45]$. Shrinkage of backfill will delay the squeezing pressure from rock mass on the filling mass and thus weaken the supporting effect. The convergent deformation of the nearby rock material into the backfilled openings or stope effected by excavation and ground stresses has a competing effect with the possible shrinkage and expansion deformation of the backfill in terms of interaction forces. In addition, after the backfill is poured into the stope, a hardening process occurs in the backfill, and its strength and stiffness greatly change over time and not evenly distributed throughout the backfilled stope, resulting in differences in the supporting force on the surrounding rock mass. The squeezing force from surrounding mass on the filling mass also changes with the time-dependent creep behavior of the nearby rock material [18], which may result in an interaction time domain and a completely noninteraction time domain as shown in Figure 1.

In this study, we assume that the interaction between mine fill and the nearby rock material conforms to the deformation harmony relation; thus, the interaction force can be set as $q(t)$. Then, we consider the hardening process of the mine backfill, the creep behavior of the nearby rock material, and the shrinkage strain of filling to form a unified spatial-temporal coupling model of the interaction, as shown in Figure 2.

After the excavation, transient elastic stress self-adjustments occur, and the backfill does not contribute to the 


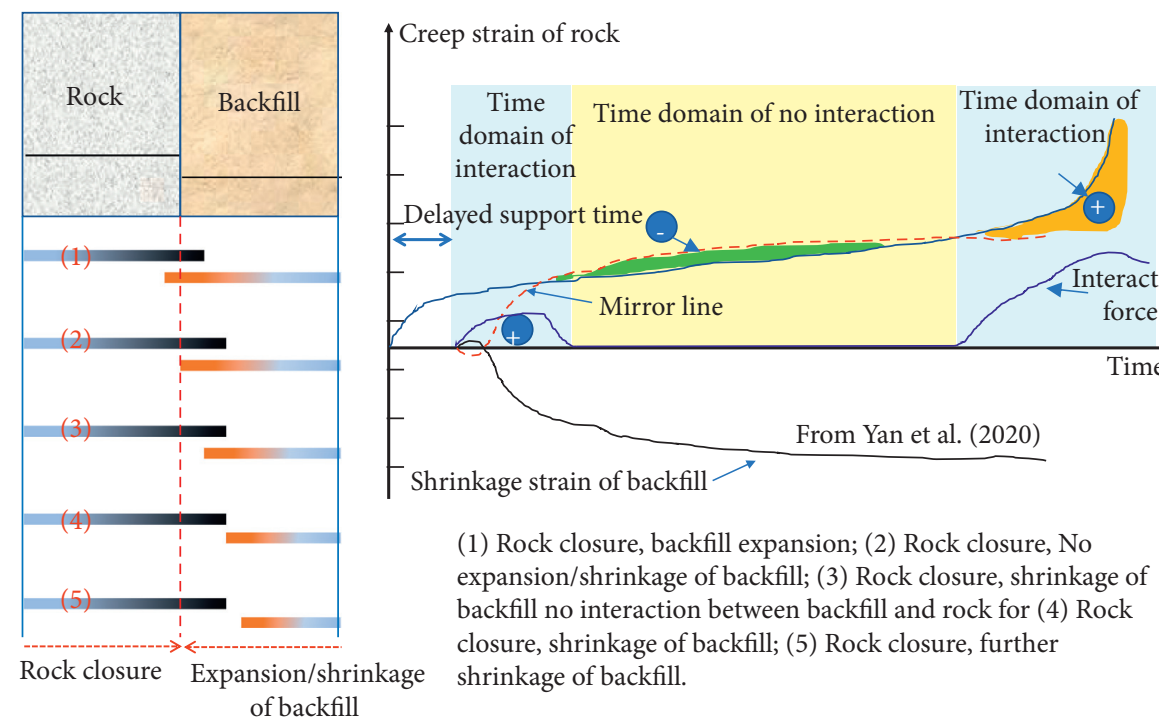

FIgURE 1: Diagram of the time-dependent interaction mechanism between backfill and rock.

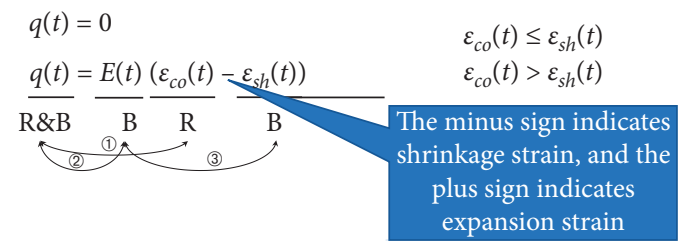

FIGURE 2: The coupling relationship between backfill stiffness, shrinkage strain, and support force (R is the rock, B is the backfill, $\varepsilon_{\mathrm{co}}(t)$ is the creep behavior of the nearby rock material, and $\varepsilon_{\mathrm{sh}}(t)$ is the backfill's shrinkage deformation).

transient deformation of that part of the surrounding rock mass but only to the subsequent creep deformation part. Three main interaction processes are as follows:

(1) The large area support of the filling material causes the stress level of the nearby rock material to change, which changes the size and rate of the time-dependent behavior of the nearby rock material. The compression force on backfill produced by the creep behavior of the nearby rock matrices can change the supporting force of backfilling on the rock material, which is a bidirectional coupling process.

(2) The hardening process of the backfill is usually influenced by the cement hydration process, and the changes of elastic modulus and stiffness are timesensitive and are also governed by water-to-cement $(w / c)$ ratio, concentration, additives, curing conditions, and other factors. The squeezing force exerted on the backfill by the surrounding rock mass puts the backfill under stress curing conditions, which in turn affects the change of elastic modulus and strength.

(3) The changes in the backfill's elastic modulus and stiffness will affect the shrinkage and expansion strain, which can greatly affect the elastic modulus and stiffness performance of backfilling, mainly in the internal structural damage caused by the incongruent deformation.

\section{Proposed Analytical Solution}

\subsection{Viscoelastic Theory Solution}

3.1.1. Infinite Round Hole under Weak Support of Backfilling. In this study, it is presumed that the evenly distributed supporting force generated by the backfill on the surrounding rock mass is $q(t)$, and then

$$
q(t)=E_{b} \sqrt{\left(\varepsilon_{r}^{2}+\varepsilon_{\theta}^{2}\right)} .
$$

At the perimeter of the round hole, $\varepsilon_{\theta}=0$ and $q(t)=E_{b}\left[\varepsilon_{r}(t)-\varepsilon_{r}(0)\right]$, where $\varepsilon_{r}(0)$ is the initial strain value at the moment when the rheological behavior of the nearby rock material begins, i.e., the elastic convergence value after the excavation effect. $\varepsilon_{r}(t)$ is the strain at time ' $t$ ' of creep of the nearby rock material. The elastic modulus $E_{b}$ of the backfill is time-dependent and a function of time. Figure 3 demonstrates a theoretical model of the deformation of the backfill with evenly distributed weak support and perimeter rock mass under plane strain conditions affected by the stresses at the remote site. 
The expressions of radial stress $\sigma_{r}[t]$, circumferential stress $\sigma_{\theta}[t]$, and shear stress $\tau_{r \theta}$ under the influence of backfill support are as follows:

$$
\left\{\begin{array}{l}
\sigma_{r}[t]=-\frac{p+\lambda p}{2}\left(1-\frac{a^{2}}{r^{2}}\right)+\frac{p-\lambda p}{2}\left(1-\frac{4 a^{2}}{r^{2}}+\frac{3 a^{4}}{r^{4}}\right) \cos 2 \theta-\frac{a^{2} q(t)}{r^{2}} \\
\sigma_{\theta}[t]=-\frac{p+\lambda p}{2}\left(1+\frac{a^{2}}{r^{2}}\right)-\frac{p-\lambda p}{2}\left(1+\frac{3 a^{4}}{r^{4}}\right) \cos 2 \theta+\frac{a^{2} q(t)}{r^{2}} \\
\tau_{r \theta}=-\frac{p-\lambda p}{2}\left(1+\frac{2 a^{2}}{r^{2}}-\frac{3 a^{4}}{r^{4}}\right) \sin 2 \theta \\
\mathbb{C}
\end{array}\right.
$$

The Hoek law is expressed by deviator stress and deviator strain, and creep strain is introduced $e_{c}$ :

$$
e_{\text {total }}=e_{e}+e_{c}=\frac{S_{i j}}{2 G}+e_{c} .
$$

The following empirical formula is used for the creep constitutive equation of surrounding rock mass for its convenience for parameter acquisition and engineering application [46]:

$$
e_{i j}=\frac{3}{2} S_{i j} A \sigma_{e}\left[\varepsilon_{r}(t)\right]^{m-1} t^{n} \exp \left(\frac{-\Delta H}{R T}\right) .
$$

Then, the strain expression is as follows:

$$
\left\{\begin{array}{l}
\varepsilon_{r}(t)=\varepsilon_{m}+\frac{\sigma_{r}[t]-\sigma_{m}}{2 G}+\left(\sigma_{r}[t]-\sigma_{m}\right) \frac{3}{2} A \sigma_{e}[t]^{m-1} t^{n} \exp \left(\frac{-\Delta H}{R T}\right), \\
\varepsilon_{\theta}(t)=\varepsilon_{m}+\frac{\sigma_{\theta}[t]-\sigma_{m}}{2 G}+\left(\sigma_{\theta}[t]-\sigma_{m}\right) \frac{3}{2} A \sigma_{e}[t]^{m-1} t^{n} \exp \left(\frac{-\Delta H}{R T}\right), \\
\varepsilon_{z}=0
\end{array}\right.
$$

where $\sigma_{z}=\mu\left(\sigma_{r}+\sigma_{\theta}\right)$, mean stress $\sigma_{m}=((1+\mu)$ / 3) $\left[\sigma_{r}+\sigma_{\theta}\right]$, mean strain $\varepsilon_{m}=\left(\sigma_{m} / E\right)(1-2 \mu)$, and mean effective stress $\sigma_{e}[t]=$ $\sqrt{(3 / 2)\left[\left(\sigma_{r}-\sigma_{m}\right)^{2}+\left(\sigma_{\theta}-\sigma_{m}\right)^{2}+\left(\sigma_{z}-\sigma_{m}\right)^{2}+2 \tau_{r \theta}^{2}\right]}$.

Therefore, under the effect of the interaction between mine filling and the nearby rock material, the radially viscoelastic strain $\varepsilon_{r}(t)$ and tangentially viscoelastic strain $\varepsilon_{\theta}(t)$ of the nearby rock material are, respectively, as follows:

$$
\left\{\begin{array}{l}
\varepsilon_{r}(t)=\varepsilon_{m}+\left\{\mathbb{A}-\frac{a^{2} q(t)}{r^{2}}-\sigma_{m}\right\}\left[\frac{(1+\mu)}{E}+\left(\frac{3}{2} A \sigma_{e}[t]^{m-1} t^{n} \exp \left(-\frac{\Delta H}{R T}\right)\right)\right], \\
\varepsilon_{\theta}(t)=\varepsilon_{m}+\left\{\mathbb{B}+\frac{a^{2} q(t)}{r^{2}}-\sigma_{m}\right\}\left[\frac{(1+\mu)}{E}+\left(\frac{3}{2} A \sigma_{e}[t]^{m-1} t^{n} \exp \left(-\frac{\Delta H}{R T}\right)\right)\right] .
\end{array}\right.
$$

Equation (6) contains the strain term on left/right sides, and the change of the support force may also have some influence on the mean effective stress $\sigma_{\mathrm{e}}$, so it cannot be solved explicitly but can be solved iteratively by MATLAB to obtain $\varepsilon_{r}(t)$. In fact, for the weak support generated by the backfill, the explicit solution by treating the variation of the effective stress $\sigma_{\mathrm{e}}[t]$ as independent variation of the radial strain $\varepsilon_{r}(t)$ is almost the same as the implicit solution obtained from the numerical solution as conformed in Figure 4 (see the next section) so that the explicit expression of $\varepsilon_{r}(t)$ can be used in the subsequent theoretical derivation. The approximation is proved, where the initial elastic strain $\varepsilon_{r}(0)$ is as follows: 


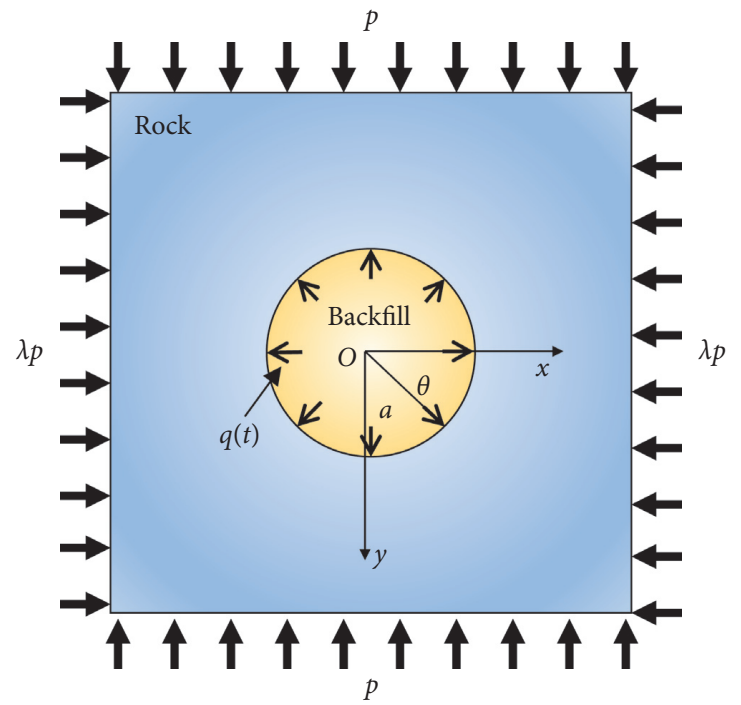

FIGURE 3: Schematic of the contact between weak fill support and nearby rock material deformation.

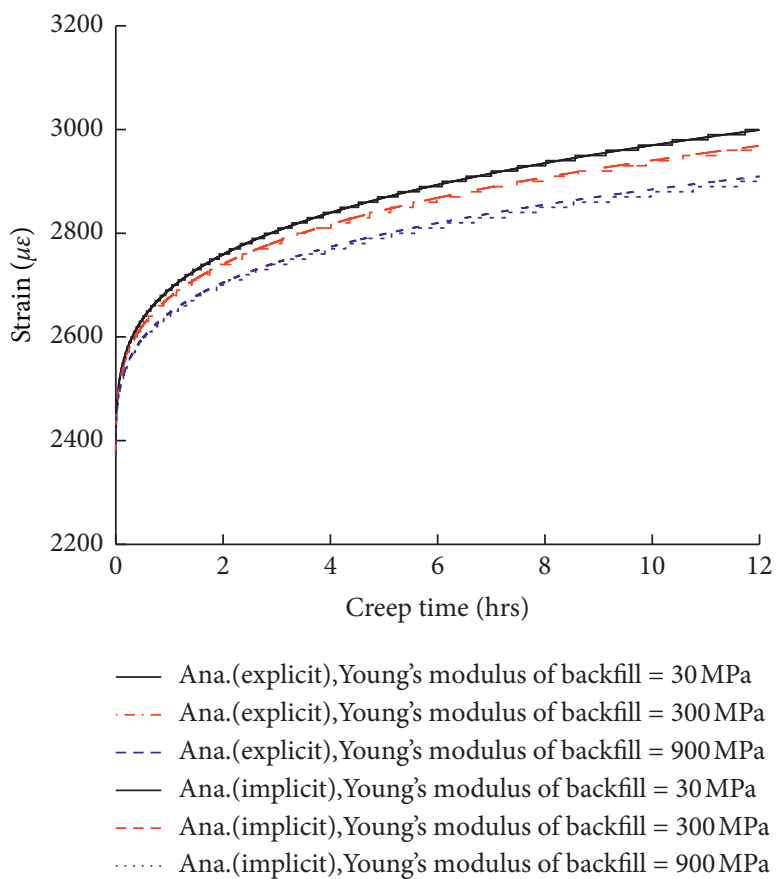

FIgURE 4: Results of coupled implicit solution and uncoupled explicit solution.

$\varepsilon_{r}(0)=\varepsilon_{m}+\left(\mathbb{A}-\sigma_{m}\right) \frac{(1+\mu)}{E}$.

3.1.2. Appraisal of Analytical/Numerical Results. To attest the rationality of the theoretical model in the earlier section, a comparative validation analysis is performed using numerical simulations considering the same boundary conditions and input parameters according to the plane strain problem. To save calculation time, the $1 / 4$ axisymmetric model is selected, as shown in Figure 5. The elastic model is chosen to be the constitutive model of the backfill. A monitoring point is set at $\mathrm{P}_{1}$ to compare with the theoretical solution of equation (6). The detailed input factors of the numerical/analytical models are shown in Table 1.

The comparison results are clearly shown in Figures 6 and 7. The change of the elastic modulus of backfill can change the stress distribution of surrounding rock mass. The theoretical solution is consistent with the numerical simulation, which verifies the accuracy of the approach obtained in the earlier section by considering the viscoelastic strain of the nearby rock material under the filling support effect.

In addition, if in hypothesis (6), i.e., $\sigma_{\mathrm{e}}[t]=\sigma_{\mathrm{e}}$, then

$$
\mathbb{D}=\frac{(1+\mu)}{E}+\frac{3}{2} A \sigma_{e}^{m-1} t^{n} \exp \left(-\frac{\Delta H}{R T}\right) \text {. }
$$




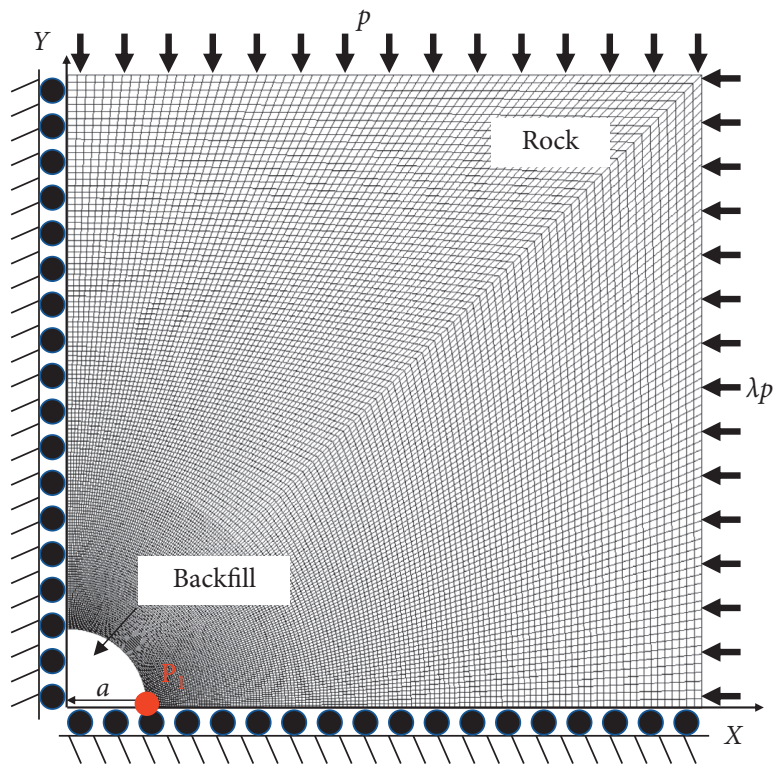

Figure 5: Numerical model of creep behavior of nearby rock material under the filling support effect (P1 is the extracted comparison data point).

TABLE 1: Input parameters of the numerical model and analytical model.

\begin{tabular}{lccc}
\hline Parameters & Analytical results & Numerical results & Unit \\
\hline Rock material-elastic modulus $E_{\mathrm{r}}$ & 8.4 & 8.4 & $\mathrm{GPa}$ \\
Rock material-Poisson ratio $\nu_{\mathrm{r}}$ & 0.29 & 0.29 & 1 \\
Mine backfill-elastic modulus $E_{b}$ & $0,30,300,900$ & $0,30,300,900$ & $\mathrm{MPa}$ \\
Mine backfill-Poisson's ratio $\nu_{\mathrm{b}}$ & 0.33 & 0.33 & 10 \\
Lateral earth pressure $p$ & 10 & 1 & $\mathrm{MPa}$ \\
Lateral earth pressure ratio $\lambda$ & 1 & 3 & 1 \\
Radius of circular hole $a$ & 3 & 3.02608 & $\mathrm{~m}$ \\
Radius of point $\mathrm{P}_{1}$ position $r$ & $3.02608^{*}$ & $\mathrm{~m}$ \\
\hline
\end{tabular}

Note. ${ }^{*}$ denotes that it is important to consider the relationship of the difference between the coordinates of the unit stress and the node displacement in the numerical model when comparing with the numerical simulation. Therefore, the $r$ value here should be the coordinates of the center point of the unit in the numerical model since it is at these coordinates that the calculated data can be compared with the theoretical solution.

On the basis of equation $(6), \varepsilon_{r}(t)$ can be isolated to obtain an explicit approximate expression of the viscoelastic strain of the surrounding rock under the support of the backfill:

$$
\varepsilon_{r}(t)=\frac{\varepsilon_{m}+\left\{\mathbb{A}-\sigma_{m}\right\} \mathbb{D}+\left(\left(a^{2} E_{b} \varepsilon_{r 0}(t=0) \mathbb{D}\right) / r^{2}\right)}{1+\left(\left(a^{2} E_{b} \mathbb{D}\right) / r^{2}\right)} .
$$

Figure 4 shows that the coupled implicit solution and the uncoupled explicit solution are essentially the same. For the hypothesis shown above, the explicit solution can be used to examine the impact of mine backfilling on creep behavior of nearby rock material. To a certain extent, the size of backfill stiffness influences the creep behavior of the surrounding rock mass.

3.1.3. Effect of Delay Backfill. Usually, after excavation, a stope backfilling requires a certain amount of preparation time and cannot be backfilled immediately. To determine the optimal support time for a specific stope and a filling mass, we need to consider the filling capacity and the condition of the nearby rock material. We need to study the support timing of filling throughout the creep behavior of the nearby rock material. Thus, considering the existence of a delayed support time of $t_{d}$ for the backfill,

$$
q(t)=E_{b}\left[\varepsilon_{r}(t)-\varepsilon_{r}(0)-\varepsilon_{\text {delay }}\left(t_{d}\right)\right]
$$

where $\varepsilon_{\text {delay }}\left(t_{d}\right)$ is the amount of creep deformation that occurs in the filler body after the creep deformation of the surrounding rock has gone through $t_{d}$. The specific form of $\varepsilon_{\text {delay }}\left(t_{d}\right)$ is as follows:

$$
\varepsilon_{\text {delay }}\left(t_{d}\right)=\left(\mathbb{A}-\sigma_{m}\right) \frac{3}{2} A \sigma_{e}\left[t_{d}\right]^{m-1} t_{d}^{n} \exp \left(\frac{-\Delta H}{R T}\right) .
$$

Therefore, the viscoelastic strain of the surrounding rock body when considering the delayed support time of the backfill is solved as follows: 


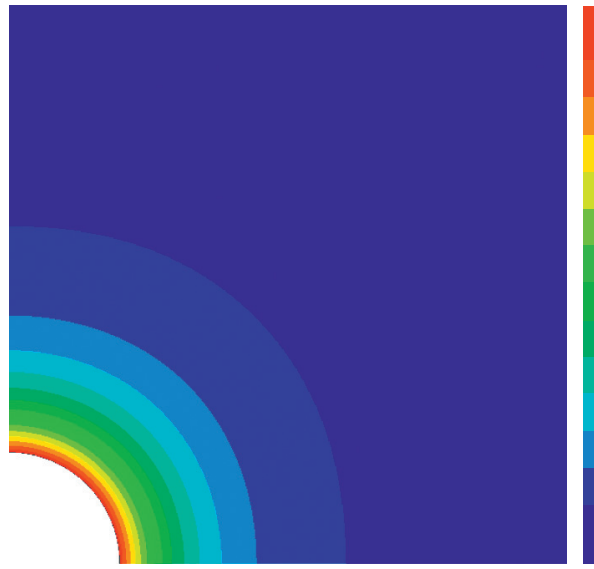

$4.6484 E+07$ $4.5000 E+07$ $4.2500 E+07$ $4.0000 E+07$ $3.7500 E+07$ $3.5000 E+07$ $3.2500 E+07$ $3.0000 E+07$ $2.7500 E+07$ $2.5000 E+07$ $2.2500 E+07$ $2.0000 E+07$ $1.7500 E+07$ $1.5000 E+07$ $1.2500 E+07$ $1.0909 E+07$

(a) Von Mises equivalent Stress $(\mathrm{Pa})$

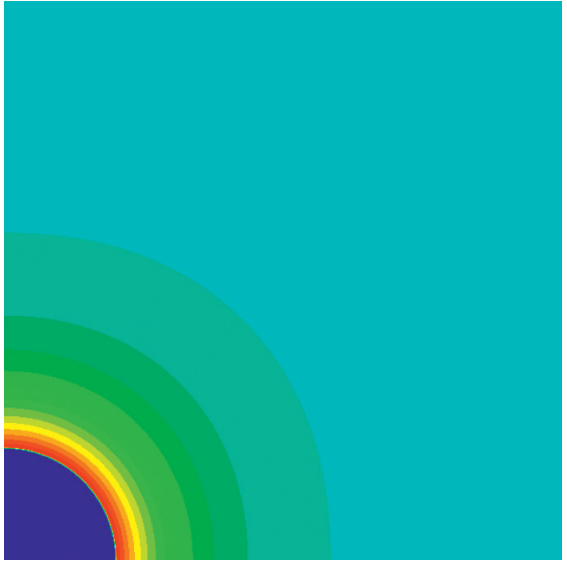

(c)

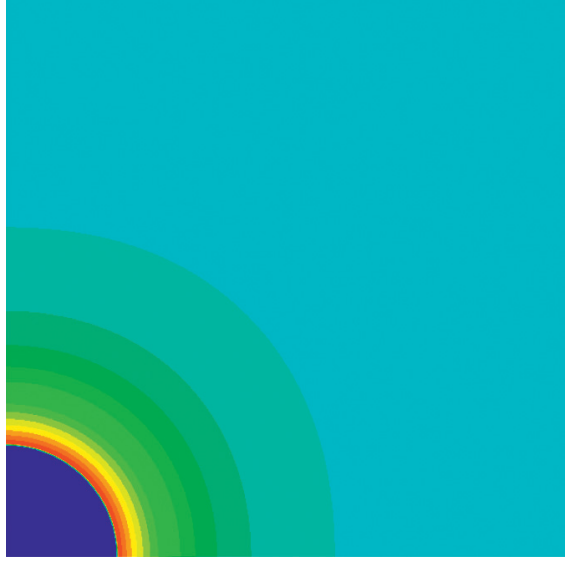

(b)

Von Mises equivalent Stress $(\mathrm{Pa})$

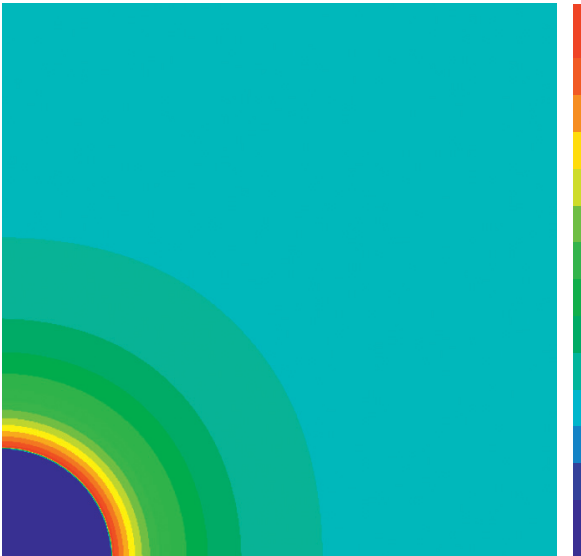

$4.3855 E+07$ $4.2500 E+07$ $4.0000 E+07$ $3.7500 E+07$ $3.5000 E+07$ $3.2500 E+07$ $3.0000 E+07$ $2.7500 E+07$ $2.5000 E+07$ $2.2500 E+07$ $2.0000 E+07$ $1.7500 E+07$ $1.5000 E+07$ $1.2500 E+07$ $1.0000 E+07$ $7.5000 E+06$ $5.0000 E+06$ $2.5000 E+06$ $2.5327 E+05$

(d)

Figure 6: Contour of Mises equivalent stress of rock under the influence of different backfill-elastic modulus. (a) Nonbackfill; $(\mathrm{b})(E)_{b}=30 \mathrm{MPa}$; (c) $(E)_{b}=300 \mathrm{MPa}$; (d) $(E)_{b}=900 \mathrm{MPa}$.

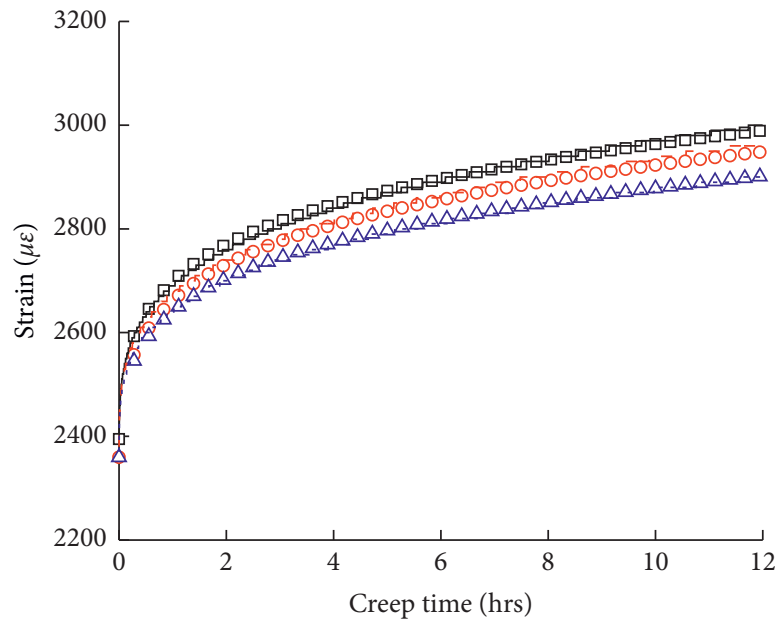

- Num., Young's modulus of backfill $=30 \mathrm{MPa}$

- Num., Young's modulus of backfill $=300 \mathrm{MPa}$

$\triangle \quad$ Num., Young's modulus of backfill $=900 \mathrm{MPa}$

- Ana.(implicit), Young's modulus of backfill $=30 \mathrm{MPa}$

- - Ana.(implicit), Young's modulus of backfill $=300 \mathrm{MPa}$ Ana.(implicit), Young's modulus of backfill $=900 \mathrm{MPa}$

Figure 7: Comparison of viscoelastic theoretical solution and numerical simulation of infinite circular hole in backfill support. 


$$
\left\{\begin{array}{l}
\varepsilon_{r}(t)=\varepsilon_{m}+\left\{\mathbb{A}-\frac{a^{2} E_{b}\left[\varepsilon_{r}(t)-\varepsilon_{r}(0)-\varepsilon_{\text {delay }}\left(t_{d}\right)\right]}{r^{2}}-\sigma_{m}\right\}\left[\frac{(1+\mu)}{E}+\left(\frac{3}{2} A \sigma_{e}[t]^{m-1} t^{n} \exp \left(-\frac{\Delta H}{R T}\right)\right)\right] \\
\varepsilon_{\theta}(t)=\varepsilon_{m}+\left\{\mathbb{B}+\frac{a^{2} E_{b}\left[\varepsilon_{r}(t)-\varepsilon_{r}(0)-\varepsilon_{\text {delay }}\left(t_{d}\right)\right]}{r^{2}}-\sigma_{m}\right\}\left[\frac{(1+\mu)}{E}+\left(\frac{3}{2} A \sigma_{e}[t]^{m-1} t^{n} \exp \left(-\frac{\Delta H}{R T}\right)\right)\right] \\
\varepsilon_{r 0}(t=0)=\varepsilon_{m}+\left(\mathbb{A}-\sigma_{m}\right) \frac{(1+\mu)}{E} .
\end{array}\right.
$$

Then, the uncoupled solution of the radial viscoelastic strain $\varepsilon_{r}(t)$ of the nearby rock material can be integrated as follows:

$$
\varepsilon_{r}(t)=\frac{\varepsilon_{m}+\left\{\mathbb{A}-\sigma_{m}\right\} \mathbb{D}+\left(\left(a^{2} E_{b}\left(\varepsilon_{r}(0)+\varepsilon_{\text {delay }}\left(t_{d}\right)\right) \mathbb{D}\right) / r^{2}\right)}{1+\left(\left(a^{2} E_{b} \mathbb{D}\right) / r^{2}\right)} .
$$

3.1.4. Effect of Backfills Hardening Process. Regardless of the type of tailings and cement, the strength of backfill will go through a rapid development phase at the beginning and a final stabilization phase (and sometimes a deterioration phase, which is not considered in this study). As shown in Figure 8, the addition of different types of binder ultimately aims to change the rate parameter $\kappa$ for strength acquisition in the curve, i.e., $\kappa_{2}$ can be considered as the higher rate of backfills strength obtained. The evolution of the backfill strength during the hardening process as a function of curing time is as follows:

$$
\begin{cases}\operatorname{UCS}(t)=0, & t<t_{d} \\ \mathrm{UCS}(t)=\mathrm{UCS}_{\infty}[1-\exp (-\kappa t)], & t \geq t_{d}\end{cases}
$$

where $\mathrm{UCS}_{\infty}$ is the final strength obtained by the backfill and $\kappa$ is the rate of backfills strength obtained.

Previous research indicated that there exists frequently a certain direct link between strength gaining of cementitious backfill and the modulus of elasticity $[47,48]$. This is also conformed by our own laboratory test results for cemented backfill (Figure 9). Thus, it is practical to presume that elastic modulus and strength of backfill during hardening process have the following relation:

$$
E(t)=K_{(E / \mathrm{UCS})} \mathrm{UCS}(t),
$$

where $K_{(E / \mathrm{UCS})}$ can be set equal to 218 as shown in Figure 9.

Thus, by presenting equation (15) into (13), the appearance of viscoelastic strain of the nearby rock material under the backfill support effect by considering the hardening process of mine backfilling can be well obtained.

\subsection{Analytical Model of Time-Dependent Stress Arching Effect} in Backfill. Figure 10 demonstrates that in some cases, the area and volume of the backfilled stope can be assumed to be approximately circular in the vertical direction, and the vertical depth is greater than the width of the cross section. From this, we can use the viscoelastic solution from the plane strain model obtained in the previous section to analyze the temporal properties of the backfill's stress distribution.

Lateral pressure $P$ is expressed as follows:

$$
p=\eta\left(p_{0}+\rho_{r} g h\right)
$$

where $\eta$ is the ratio of horizontal/vertical stress, $p_{0}$ is the stress of overlying strata of the backfilled opening or stope, $\rho_{r}$ is the rock's density, $g$ is the gravitational acceleration, and $h$ is the depth of the backfilled opening or stope.

The $p$ in $A$ and $\mathbb{B}$ is separated as follows:

$$
\left\{\begin{array}{l}
\mathbb{A}=-\frac{p+\lambda p}{2}\left(1-\frac{a^{2}}{r^{2}}\right)+\frac{p-\lambda p}{2}\left(1-\frac{4 a^{2}}{r^{2}}+\frac{3 a^{4}}{r^{4}}\right) \cos 2 \theta=p \mathbb{A}^{\prime}, \\
\mathbb{B}=-\frac{p+\lambda p}{2}\left(1+\frac{a^{2}}{r^{2}}\right)-\frac{p-\lambda p}{2}\left(1+\frac{3 a^{4}}{r^{4}}\right) \cos 2 \theta=p \mathbb{B}^{\prime} .
\end{array}\right.
$$

The mean strain $\varepsilon_{m}$ and mean stress $\sigma_{m}$ can be expressed as follows:

$$
\begin{aligned}
& \varepsilon_{m}=p \frac{(1-2 \mu)(1+\mu)}{3 E}\left[\mathbb{A}^{\prime}+\mathbb{B}^{\prime}\right], \\
& \sigma_{m}=p \frac{(1+\mu)}{3}\left[\mathbb{A}^{\prime}+\mathbb{B}^{\prime}\right] .
\end{aligned}
$$

The instantaneous elastic strain $\varepsilon_{r}(0)$ formed by initial extraction of the nearby rock material and the creep stress variable $\varepsilon_{\text {delay }}\left(t_{d}\right)$ generated by delayed backfilling of the nearby rock material are as follows:

$$
\begin{aligned}
\varepsilon_{r}(0) & =\varepsilon_{m}+\left(\mathbb{A}-\sigma_{m}\right) \frac{(1+\mu)}{E} \\
\varepsilon_{\text {delay }}\left(t_{d}\right) & =\left(\sigma_{r}\left(t_{d}\right)-\sigma_{m}\right) \frac{3}{2} A \sigma_{e}^{m-1} t_{d}^{n} \exp \left(\frac{-\Delta H}{R T}\right) .
\end{aligned}
$$

Consequently, the expression of $\varepsilon_{r}(t)$ of the radial viscous strain of the nearby rock material can be given as follows:

$$
\varepsilon_{r}(t)=\frac{\varepsilon_{m}+\left\{\mathbb{A}-\sigma_{m}\right\} \mathbb{D}+\left(\left(a^{2} E_{b}\left(\varepsilon_{r}(0)+\varepsilon_{\text {delay }}\left(t_{d}\right)\right) \mathbb{D}\right) / r^{2}\right)}{1+\left(\left(a^{2} E_{b} \mathbb{D}\right) / r^{2}\right)}=p \mathbb{U},
$$




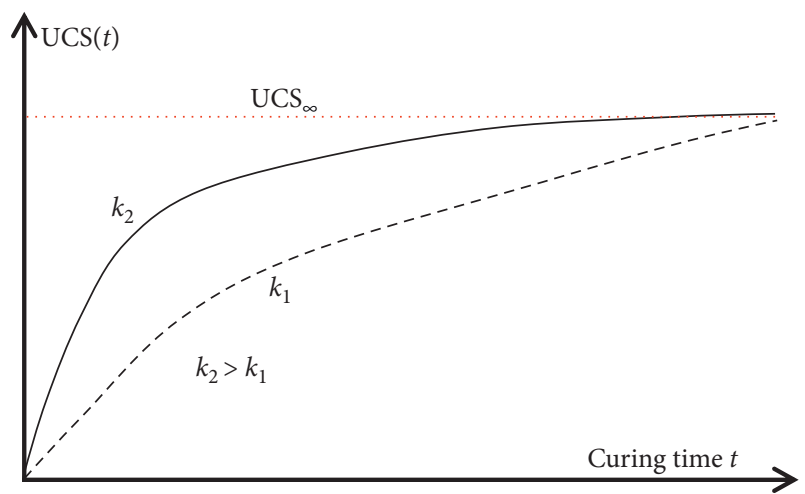

Figure 8: Curves of relationship between backfills strength and curing age.

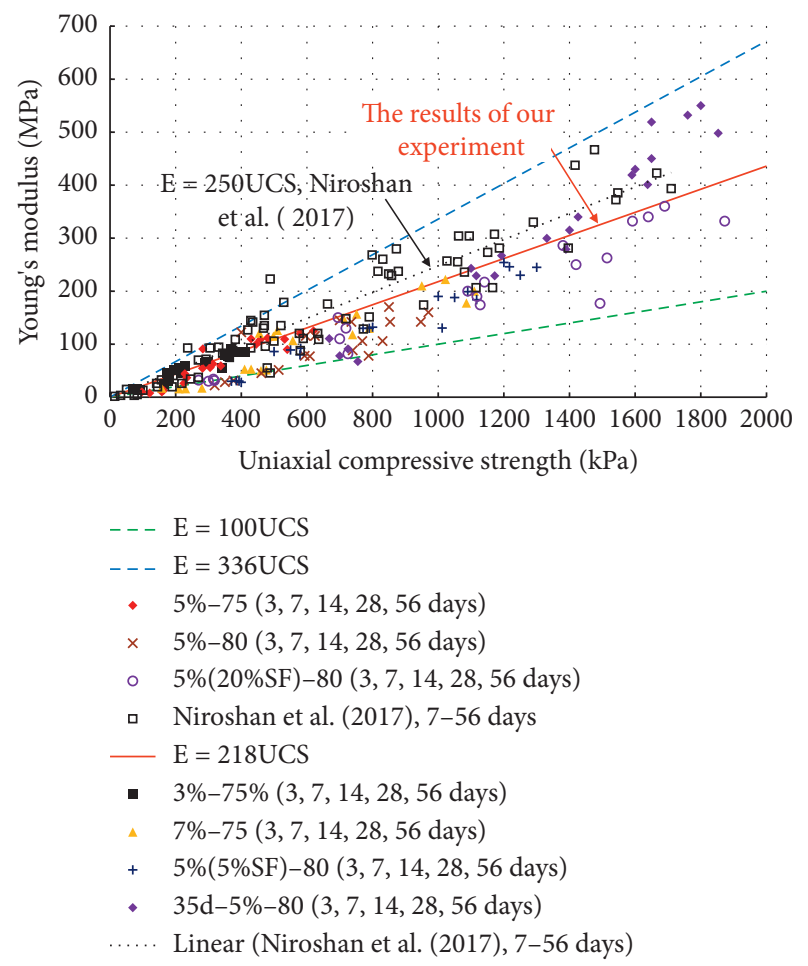

FIGURE 9: Plot of the change in the elastic modulus with the strength of cemented mine backfill.

where

$$
\begin{aligned}
& \mathbb{D}=\frac{(1+\mu)}{E}+\frac{3}{2} A \sigma_{e}^{m-1} t^{n} \exp \left(-\frac{\Delta H}{R T}\right), \\
& \mathbb{U}=\frac{\varepsilon_{r}(t)}{p} .
\end{aligned}
$$

The expression of strain $\varepsilon_{r c}(t)$ acting on backfilling by the creep behavior of the nearby rock material is given as follows:

$$
\varepsilon_{r c}(t)=\mathbb{U} p-\varepsilon_{r 0}-\varepsilon_{\text {delay }}\left(t_{d}\right) .
$$

The gravity on the differential element body is as follows:

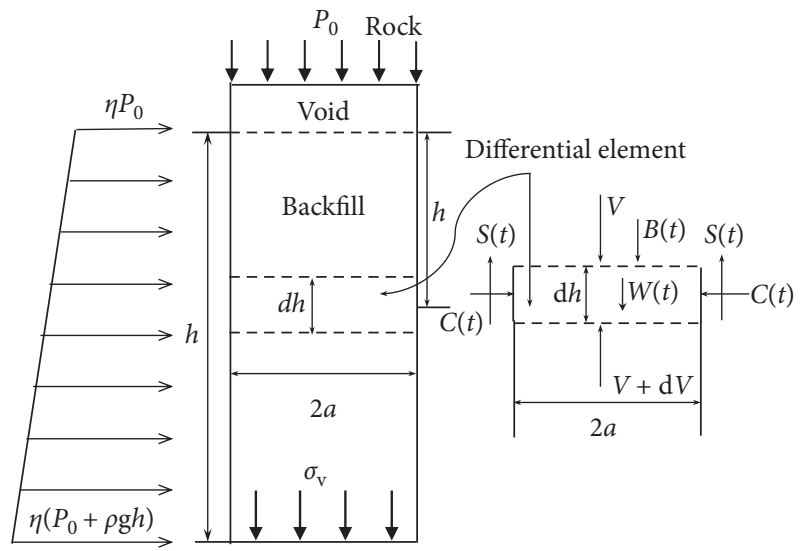

Figure 10: Diagram of approximate circular cross section high filling stope backfill force.

$$
W=\gamma \pi a^{2} \mathrm{~d} h .
$$

When the creep behavior happens in the nearby rock material, the backfill pore structure is compressed tightly when the backfill is squeezed. In addition, backfill drainage produces consolidation effect, which reduces the backfill's porosity, and the backfill's bulk density gradually increases with the development of creep deformation. Thus, there are

$$
\gamma=\gamma_{0}+\chi E_{b} \varepsilon_{r c}(t)=\gamma_{0}+\chi E_{b}\left(\mathbb{U} p-\varepsilon_{r 0}-\varepsilon_{\text {delay }}\left(t_{d}\right)\right), \quad\left(\gamma_{0} \leq \gamma \leq \gamma_{s}\right) .
$$

Among them, $\chi$ represents the compaction capacity of backfill under confining pressure and is the empirical coefficient related to the characteristics of backfill materials, $\gamma_{0}$ is the initial backfill density, and $\gamma_{s}$ is the tailings bulk density.

Assuming that the horizontal plane of the differential element is subject to the average vertical stress with uniform distribution, the normal pressure $C$ generated by the surrounding rock and the friction force $S$ (without considering the interfacial bonding forces) are, respectively, as follows:

$$
\begin{aligned}
C & =2 \pi a \sigma_{h}=2 \pi a\left[K_{p} \sigma_{v}+E_{b}\left(\mathbb{U} p-\varepsilon_{r 0}-\varepsilon_{\text {delay }}\left(t_{d}\right)\right)\right], \\
S & =C \tan \delta \mathrm{d} h=2 \pi a\left[K_{p} \sigma_{v}-E_{b}\left(\mathbb{U} p-\varepsilon_{r 0}-\varepsilon_{\text {delay }}\left(t_{d}\right)\right)\right] \tan \delta \mathrm{d} h .
\end{aligned}
$$

According to Poisson's effect, the differential element is squeezed by the horizontal force from the surrounding rock mass, and it tends to squeeze downward in the vertical direction under the action of gravity. Therefore, the reaction coefficient tends toward the passive condition [49], and the equality in the vertical way can be inferred as follows:

$$
V+\mathrm{d} V+S=W+V+B,
$$

where $B$ refers to the vertical squeezing pressure caused by Poisson's effect in the vertical direction of horizontal squeezing on the differential element body:

$$
B=v E_{b} \varepsilon_{r c}(t) \mathrm{d} h .
$$


Then,

$$
\begin{aligned}
& \mathrm{d} \sigma_{v} \pi a^{2}+2 \pi a\left[K_{p} \sigma_{v}-E_{b}\left(\mathbb{U} p-\varepsilon_{r 0}-\varepsilon_{\text {delay }}\left(t_{d}\right)\right)\right] \tan \delta \mathrm{d} h \\
& \quad=\left[\gamma_{0}+\chi E_{b}\left(\mathbb{U} p-\varepsilon_{r 0}-\varepsilon_{\text {delay }}\left(t_{d}\right)\right)\right] \pi a^{2} \mathrm{~d} h+v E_{b}\left(\mathbb{U} p-\varepsilon_{r 0}-\varepsilon_{\text {delay }}\left(t_{d}\right)\right) \mathrm{d} h,
\end{aligned}
$$

where $v$ is the ratio between horizontal and vertical squeezing pressure caused by the surrounding creeping rock material.
By integration,

$$
\begin{aligned}
\frac{\mathrm{d} \sigma_{v}}{\mathrm{~d} h}+ & \frac{2 K_{o} \tan \delta}{a} \sigma_{v}+\eta \rho_{r} g E_{b} \mathbb{U}\left[\frac{-2 \tan \delta}{a}-\chi-\frac{\nu}{\pi a^{2}}\right] h \\
= & {\left[\gamma_{0}+\chi E_{b}\left(\mathbb{U} \eta p_{0}-\varepsilon_{r 0}-\varepsilon_{\text {delay }}\left(t_{d}\right)\right)+\frac{\nu E_{b}\left(\mathbb{U} \eta p_{0}-\varepsilon_{r 0}-\varepsilon_{\text {delay }}\left(t_{d}\right)\right)}{\pi a^{2}}\right] } \\
& +\frac{2 E_{b} \tan \delta\left(\mathbb{U} \eta p_{0}-\varepsilon_{r 0}-\varepsilon_{\text {delay }}\left(t_{d}\right)\right)}{a} .
\end{aligned}
$$

The vertical stress $\sigma_{\mathrm{v}}$ in the backfill is obtained by solving the first-order linear nonuniform differential equations:

(1) when $\delta=0$ and $\mathscr{B}=0$, then

$$
\sigma_{v}=\frac{\mathscr{A}}{2} h^{2}+\mathscr{C} h+C
$$

where $h=0$, and then $C=0$.

(2) when $\delta \neq 0$, then

$$
\sigma_{v}=-\frac{\mathscr{A} h+\mathscr{C}}{\mathscr{B}}-\frac{\mathscr{A}}{\mathscr{B}^{2}}+\left(\frac{\mathscr{C}}{\mathscr{B}}+\frac{\mathscr{A}}{\mathscr{B}^{2}}\right) \exp (\mathscr{B} h) .
$$

Among them, when $\mathrm{h}=0, C=(\mathscr{C} / \mathscr{B})+\left(\mathscr{A} / \mathscr{B}^{2}\right)$,

$$
\begin{aligned}
\mathscr{A}= & -\eta E_{b} \rho_{r} g \mathbb{U}\left[\frac{-2 \tan \delta}{a}-\chi-\frac{\nu}{\pi a^{2}}\right], \\
\mathscr{B}= & -\frac{2 K_{o} \tan \delta}{a}, \\
\mathscr{C}= & {\left[\begin{array}{c}
\gamma_{0}+\chi E_{b}\left(\mathbb{U} \eta p_{0}-\varepsilon_{r 0}-\varepsilon_{\text {delay }}\left(t_{d}\right)\right) \\
\left.+\frac{\nu E_{b}\left(\mathbb{U} \eta p_{0}-\varepsilon_{r 0}-\varepsilon_{\text {delay }}\left(t_{d}\right)\right)}{\pi a^{2}}\right]
\end{array}\right.} \\
& +\frac{2 E_{b} \tan \delta\left(\mathbb{U} \eta p_{0}-\varepsilon_{r 0}-\varepsilon_{\text {delay }}\left(t_{d}\right)\right)}{a} .
\end{aligned}
$$

If $\gamma \geq \gamma_{s}$,

$$
\begin{aligned}
\mathrm{d} \sigma_{v} \pi a^{2}+ & 2 \pi a\left[K_{p} \sigma_{v}-E_{b}\left(\mathbb{U} p-\varepsilon_{r 0}\right)\right] \tan \delta \mathrm{d} h \\
= & \gamma_{s} \pi a^{2} \mathrm{~d} h+v E_{b}\left(\mathbb{U} \eta\left(p_{0}+\rho_{r} g h\right)-\varepsilon_{r 0}-\varepsilon_{\text {delay }}\left(t_{d}\right)\right) \mathrm{d} h, \\
\frac{\mathrm{d} \sigma_{v}}{\mathrm{~d} h}+ & \frac{2 K_{o} \tan \delta}{a} \sigma_{v}+\eta \rho_{r} g E_{b} \mathbb{U}\left[\frac{-2 \tan \delta}{a}-\frac{\nu}{\pi a^{2}}\right] h \\
= & \left(\gamma_{s}+\frac{\nu E_{b}\left(\mathbb{U} \eta p_{0}-\varepsilon_{r 0}-\varepsilon_{\text {delay }}\left(t_{d}\right)\right)}{\pi a^{2}}\right) \\
& +\frac{2 E_{b} \tan \delta\left(\mathbb{U} \eta p_{0}-\varepsilon_{r 0}-\varepsilon_{\text {delay }}\left(t_{d}\right)\right)}{a},
\end{aligned}
$$

where

$$
\begin{aligned}
\mathscr{A}= & -\eta E_{b} \rho_{r} g \mathbb{U}\left[\frac{-2 \tan \delta}{a}-\frac{\nu}{\pi a^{2}}\right], \\
\mathscr{B}= & -\frac{2 K_{o} \tan \delta}{a}, \\
\mathscr{C}= & \left(\gamma_{s}+\frac{\nu E_{b}\left(\mathbb{U} \eta p_{0}-\varepsilon_{r 0}-\varepsilon_{\text {delay }}\left(t_{d}\right)\right)}{\pi a^{2}}\right) \\
& +\frac{2 E_{b} \tan \delta\left(\mathbb{U} \eta p_{0}-\varepsilon_{r 0}-\varepsilon_{\text {delay }}\left(t_{d}\right)\right)}{a} .
\end{aligned}
$$

The horizontal stress of backfill $\sigma_{\mathrm{h}}$ is

$$
\sigma_{h}=K_{p} \sigma_{v}+E_{b}\left(\mathbb{U} p-\varepsilon_{r 0}-\varepsilon_{\text {delay }}\left(t_{d}\right)\right),
$$

where $E_{b}$ is positively correlated with the bulk density of backfill as well as the curing age. 


\section{Verification of the Offered Model}

To verify the rationality of the proposed theoretical model, a corresponding numerical model is built for simulating the backfill into the stope influenced by the creep behavior of the nearby rock material and the time-dependent stress distribution in the backfill. As shown in Figure 11, to save calculation time, the axisymmetric model is selected, the width of the backfilled stope is set at $6 \mathrm{~m}$, the height is $45 \mathrm{~m}$, and the void area of the backfilled stope is $0.5 \mathrm{~m}$. The model boundary width is set at $250 \mathrm{~m}$, and the height is set at $500 \mathrm{~m}$ in the light of Saint-Venant's principle and the trial calculation results of different mesh sizes. Finally, 151999 tetrahedral elements with a minimum size of $0.25 \mathrm{~m}$ were also constructed.

The backfill and surrounding rock mass are modeled as elastic materials. Elastic modulus and Poisson's ratio of rock and backfill can be seen in Table 1 . The specific simulation process is as follows: (1) the backfilled stope is selected at a depth of $1000 \mathrm{~m}$, the initial ground stress field conditions are given, the lateral pressure coefficient is set to 2 , and the horizontal ground stress ratio is set to 1 ; (2) excavating the filling stope and solving to equilibrium to complete the elastic equilibrium calculation under the influence of the excavation; and (3) zero the initial displacement field formed by the excavation and perform the solution calculation for the creep or time-dependent deformation of the nearby rock material with and without filling until the target time is set.

To verify the assumption in the established model that the differential elements in the horizontal direction of filling stope approximately meet the plane strain condition, this study calculates the creep deformation without filling after excavation to acquire the vertical strain of the nearby rock material. Figure 12 shows the change of vertical strain along with the height of filling stope in the creep process of adjacent surrounding rock mass. Except that the vertical strain in upper/lower sides of the backfilled stope is not close to 0 , all other places meet the requirements of plane strain; that is, the vertical strain is 0 .

To verify the validity of the theoretical solution, the simulation process does not take into account the effects of the damage caused by the excavation and the creep deformation process, i.e., the strength of the nearby rock mass is set large. The backfill is not damaged, and the effects of creep deformation of the backfill are not considered. The elastic modulus $E_{b}$ of backfilling is $300 \mathrm{MPa}$, and the comparison between the different delay times for the backfill and the different creep deformation times for the nearby rock material is shown in Figures 13(a)-13(c).

The comparison results show that in general the theoretical solution is close to the numerical simulation results, especially the development of vertical stresses in backfill influenced by creeping rock mass. The backfill's horizontal stress is influenced by the extrusion stress in lower sides of the backfilled stope by the bottom corner points, which is different from the mathematical simulation. The stress in the backfill will increase as the creep behavior of the nearby rock material develops, and this increase will become insignificant as the delay time for filling the mined-out opening or stope increases due to the compression exerted in the backfill by creeping rock material.

\section{Sample Application}

Researchers have conducted extensive theoretical analyses for underground backfilled stope where the creep behavior effect on the nearby rock material is not considered or is not apparent, and the results confirmed that the stresses in backfill present arching phenomena [50,51], which is also common in soil foundations [52]. However, when the creep deformation of the surrounding rock mass is considered, the stress distribution changes significantly and the internal stresses exceed the self-weight stresses of backfill. This form of stress distribution is closely related to the stope buried depth, lateral pressure coefficient, Young's modulus of the backfill, creep deformation of the surrounding rock mass, and delayed filling time. Based on this, these influencing parameters are analyzed in this section. Table 2 lists a specific comparison conditions.

Figure 14 demonstrates that the depth of the backfilled stope has a strong impact on its internal stress distribution of backfill. This is primarily reflected in the fact that the deeper the filling stope is, the greater the surrounding rock stress is, and the more likely the surrounding rock mass is to creep deformation under high in situ stress. Consequently, the squeezing pressure of the backfill subjected to the nearby rock deformation is greater. When the buried depth of the filled stope is $500 \mathrm{~m}$, the creep performance of the nearby rock material has a little influence on the backfill's internal stresses.

The backfill's internal stress is close to that obtained when the effect of creeping rock is not considered; that is, the stress in the lower side of the backfilled stope is less important than the self-weight stress value, and the effect of arching is noteworthy. However, when the buried depth of stope is $1000 \mathrm{~m}$ and $1500 \mathrm{~m}$, the vertical/horizontal stresses in backfilling surge intentionally, and the squeezing effect of the nearby rock material on the backfill becomes significant. This indicates that when considering the effect of creep property of the nearby rock material on the backfill's internal stress, the depth of the backfill opening or stope cannot be ignored, and there is safety hidden dangers when entering deep mining according to the standard of designing backfill strength according to the distribution of self-weight stress.

Figure 15 demonstrates that the ratio of horizontal/vertical stresses of the nearby rock material has an influence on the backfill's internal stress, which is mainly reflected in that the internal stress of the backfill is more significantly affected by the creep behavior of the nearby rock material as the lateral pressure coefficient increases. When the coefficient of lateral stresses in nearby rock material is 0.5 , the horizontal creep deformation of the nearby rock material drops and the squeezing pressure of the nearby rock material on the backfill decreases. At this time, the backfill's internal stresses are less than the self-weight stress. With a lateral pressure coefficient of 2 , the horizontal deformation capacity of the nearby rock material rises, and the stress inside the backfill increases significantly. This further indicates that when considering the creep behavior of the nearby rock material, the main reason for 


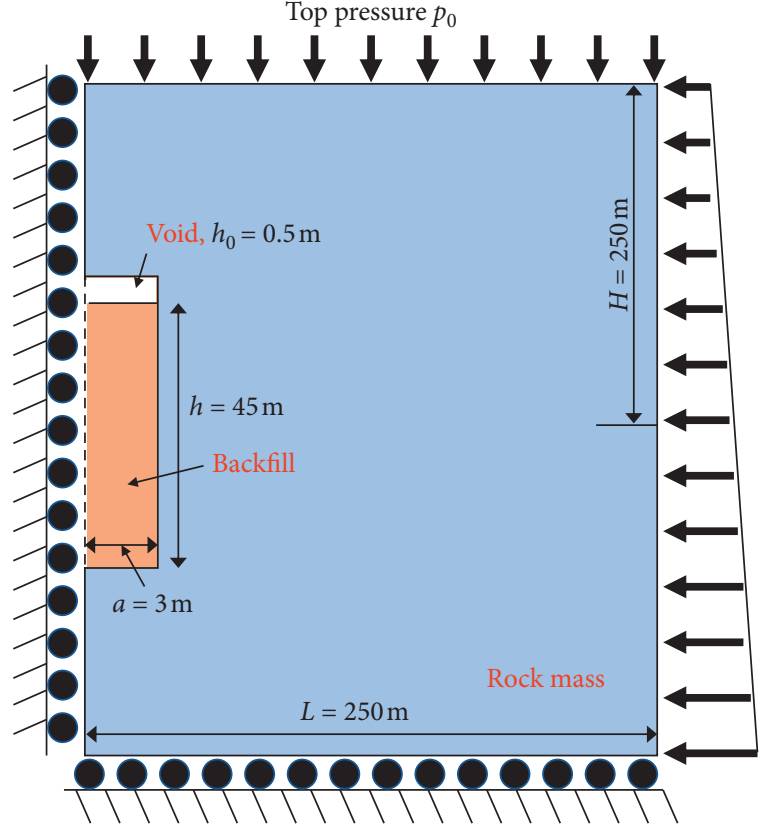

(a)

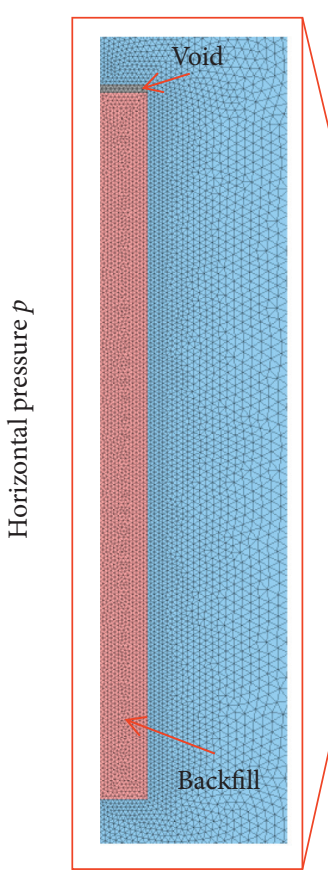

Zone number: 151999

Minimum zone size: $0.25 \mathrm{~m}$

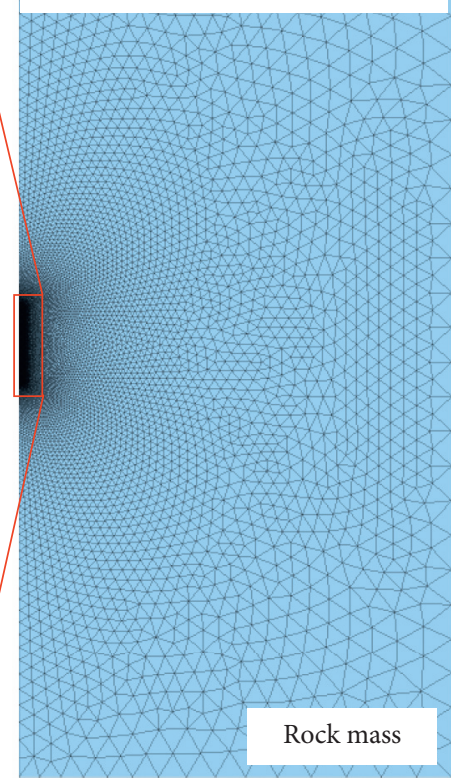

(b)

FIGURE 11: A schematic view of the numerical model: (a) size/boundary settings and (b) grid model.

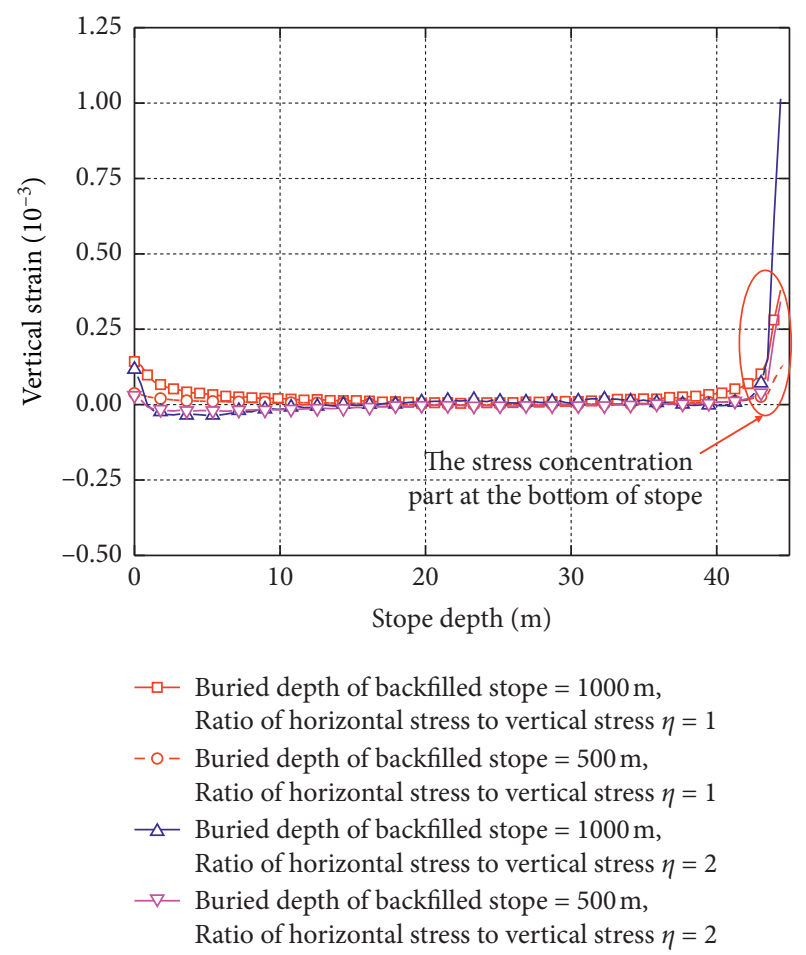

FIGURE 12: Variation of vertical strain of surrounding rock mass in stope area within stope height.

the increase in the internal stress of the backfill is the surge of the horizontal deformation capacity of the nearby rock material and the improvement of the squeezing capacity of the backfill.

As can be seen from Figure 16, with the increase in backfill's elastic modulus, the vertical and horizontal stresses in the backfill rise. With the backfill's elastic modulus of $30 \mathrm{MPa}$, the stress in the backfill is less than the self-weight stress distribution, and the horizontal stress and vertical stress distribution are close to each other.

With the rise in backfill's elastic modulus, difference between horizontal and vertical stresses increases, and both of them gradually exceed their self-weight stress. The supporting reaction force of the nearby rock material also increases with the increase in the creep behavior of the nearby rock material. The two are coupled. It reflects the passive support form of "You are strong, I am strong, you are weak, I am weak" after the backfill is filled into the mined-out opening or stope.

Figure 17 shows that the changes of the ratio between two horizontal stresses also govern the backfill's internal stress influenced by creeping rock. The stresses in backfill decrease with the rise of the ratio of horizontal stress, and the gap between horizontal stress and vertical stress of backfill will shorten. This is because, when the fixed value of horizontal stress in one direction is $0.5 \mathrm{p}$ and when the ratio is $0.5,1$, and 2 , the horizontal stress in the other direction is $p$, $0.5 \mathrm{p}$, and $0.25 \mathrm{p}$, respectively. One can see that when the horizontal stress ratio is 0.5 , the nearby rock material will be in a stress environment with high confining pressure. Relevant studies show that the creep behavior of the nearby rock material will be enhanced under high confining pressure. Therefore, the horizontal squeezing effect of the nearby rock on the interior of backfilling will increase, leading to the increase in its internal stress.

According to the numerical results of Figure 13, the delay time of backfilling also can affect the internal stress of the backfill. The greater the delay time, the more rock creep 


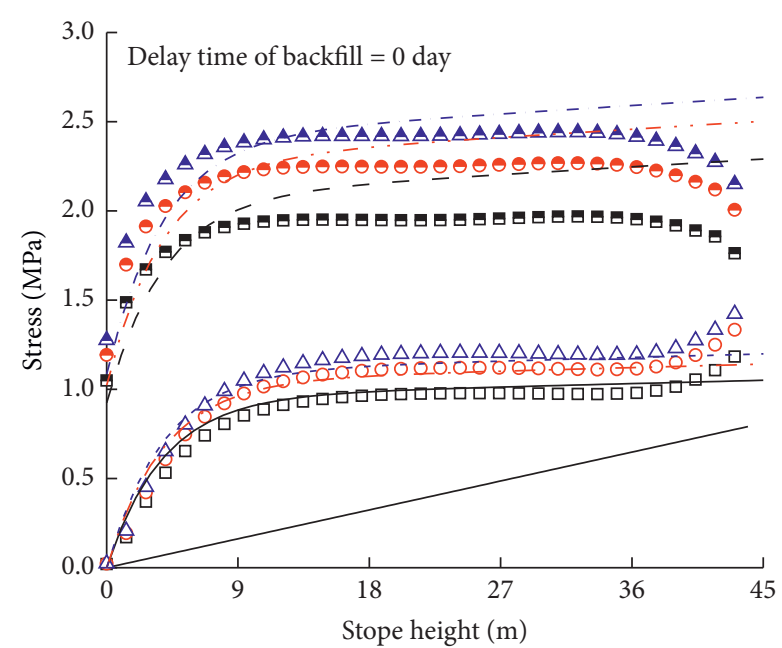

- Self-weight stress of backfill

Num., $\sigma_{\mathrm{v}}$, creep time of rock $=30$ days

- Num., $\sigma_{\mathrm{h}}$, creep time of rock $=30$ days

○ Num., $\sigma_{\mathrm{v}}$, creep time of rock $=60$ days

- Num., $\sigma_{\mathrm{h}}$, creep time of rock $=60$ days

$\Delta$ Num., $\sigma_{\mathrm{v}}$, creep time of rock $=90$ days

$\Delta$ Num., $\sigma_{\mathrm{h}}$, creep time of rock $=90$ days

- Ana., $\sigma_{\mathrm{v}}$, creep time of rock $=30$ days

- - Ana., $\sigma_{\mathrm{h}}$, creep time of rock $=30$ days

- - Ana., $\sigma_{\mathrm{v}}$, creep time of rock $=60$ days

- - Ana., $\sigma_{\mathrm{h}}$, creep time of rock $=60$ days

- - - Ana., $\sigma_{v}$, creep time of rock $=90$ days

- . Ana., $\sigma_{\mathrm{h}}$, creep time of rock $=90$ days

(a)

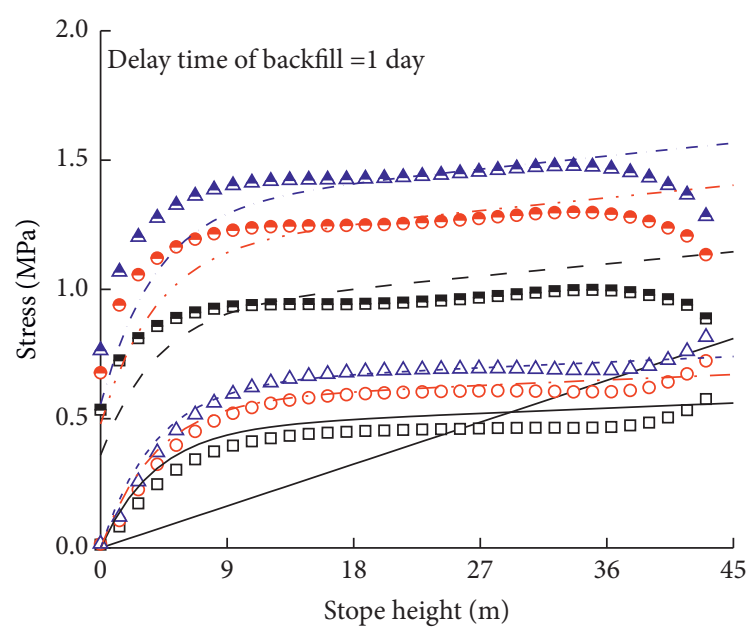

- Self-weight stress of backfill

口 Num., $\sigma_{\mathrm{v}}$, creep time of rock $=30$ days

- Num., $\sigma_{\mathrm{h}}$, creep time of rock $=30$ days

○ Num., $\sigma_{\mathrm{v}}$, creep time of rock $=60$ days

- Num., $\sigma_{\mathrm{h}}$, creep time of rock $=60$ days

$\Delta$ Num., $\sigma_{\mathrm{v}}$, creep time of rock $=90$ days

$\Delta$ Num., $\sigma_{\mathrm{h}}$, creep time of rock $=90$ days

- Ana., $\sigma_{\mathrm{v}}$, creep time of rock $=30$ days

_ _ - Ana., $\sigma_{\mathrm{h}}$, creep time of rock $=30$ days

- - Ana., $\sigma_{\mathrm{v}}$, creep time of rock $=60$ days

. . . - Ana., $\sigma_{\mathrm{h}}$, creep time of rock $=60$ days

- - - Ana., $\sigma_{\mathrm{v}}$, creep time of rock $=90$ days

. . . Ana., $\sigma_{\mathrm{h}}$, creep time of rock $=90$ days

(b)

Figure 13: Continued. 


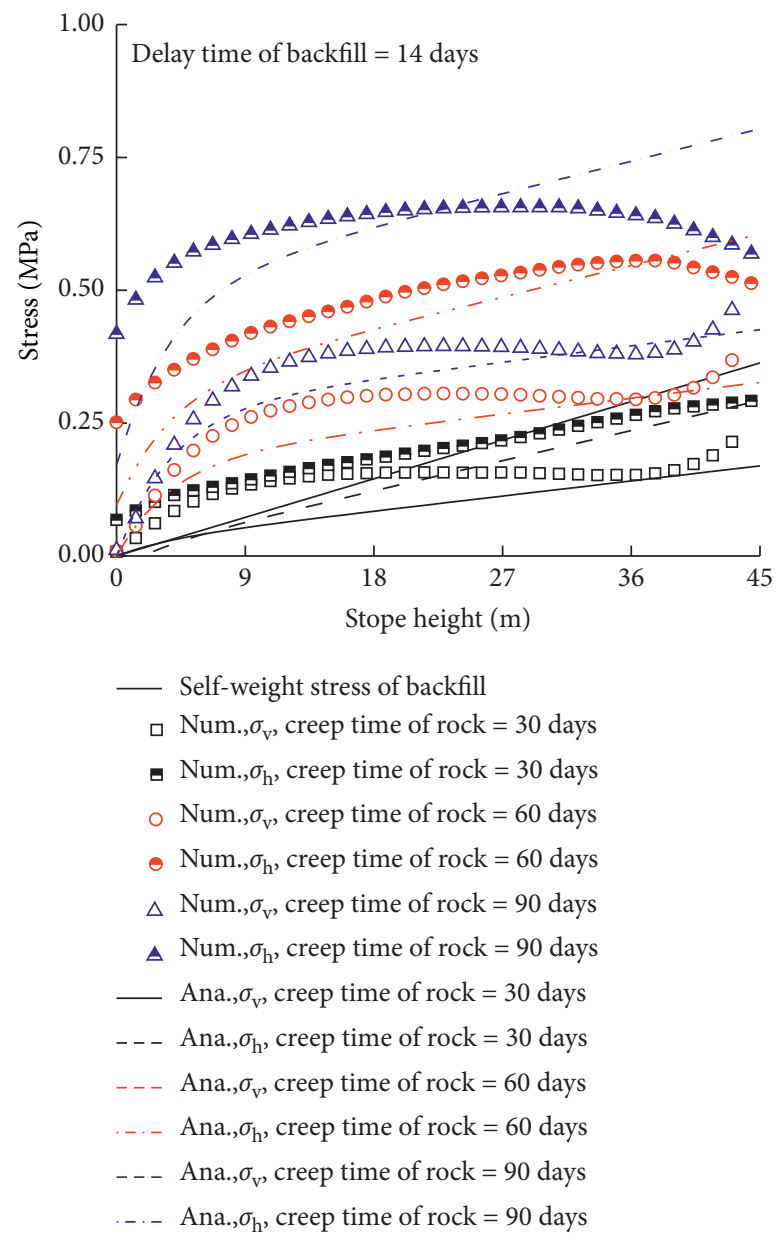

(c)

FIGURE 13: Theoretical and numerical results of time-dependent interaction between backfill and surrounding rock mass: (a) stope without delay filling; (b) delayed filling for 1-day; (c) delayed filling for 14-day.

TABle 2: Analysis of influential factors of rock creep deformation on the stress distribution of backfill.

\begin{tabular}{|c|c|c|c|c|c|c|}
\hline Factors & $\begin{array}{c}\text { Stope } \\
\text { depth }(\mathrm{m})\end{array}$ & $\begin{array}{l}\text { Lateral pressure } \\
\text { coefficient } \eta\end{array}$ & $\begin{array}{l}\text { Horizontal stress } \\
\text { ratio } \lambda\end{array}$ & $\begin{array}{l}\text { Creep time of } \\
\text { rock mass } t \\
\text { (days) }\end{array}$ & $\begin{array}{l}\text { Young's modulus of } \\
\text { backfill } E_{b}(\mathrm{MPa})\end{array}$ & $\begin{array}{c}\text { Delay time of } \\
\text { backfill } t_{d} \text { (days) }\end{array}$ \\
\hline \multirow{3}{*}{ Stope depth } & 500 & 2 & 1 & 30 & 300 & 1 \\
\hline & 1000 & 2 & 1 & 30 & 300 & 1 \\
\hline & 1500 & 2 & 1 & 30 & 300 & 1 \\
\hline \multirow{3}{*}{$\begin{array}{l}\text { Lateral pressure } \\
\text { coefficient } \eta\end{array}$} & 1000 & 0.5 & 1 & 30 & 300 & 1 \\
\hline & 1000 & 1 & 1 & 30 & 300 & 1 \\
\hline & 1000 & 2 & 1 & 30 & 300 & 1 \\
\hline \multirow{3}{*}{ Horizontal stress ratio $\lambda$} & 1000 & 2 & 0.5 & 30 & 300 & 1 \\
\hline & 1000 & 2 & 1 & 30 & 300 & 1 \\
\hline & 1000 & 2 & 2 & 30 & 300 & 1 \\
\hline \multirow{3}{*}{$\begin{array}{l}\text { Creep time of } \\
\text { surrounding rock mass } t\end{array}$} & 1000 & 2 & 1 & 30 & 300 & 1 \\
\hline & 1000 & 2 & 1 & 60 & 300 & 1 \\
\hline & 1000 & 2 & 1 & 90 & 300 & 1 \\
\hline \multirow{3}{*}{$\begin{array}{l}\text { Young's modulus of } \\
\text { backfill } \mathrm{E}_{b}\end{array}$} & 1000 & 2 & 1 & 30 & 30 & 1 \\
\hline & 1000 & 2 & 1 & 30 & 300 & 1 \\
\hline & 1000 & 2 & 1 & 30 & 900 & 1 \\
\hline \multirow{3}{*}{ Delay time of backfill $t_{d}$} & 1000 & 2 & 1 & 30 & 300 & 0 \\
\hline & 1000 & 2 & 1 & 30 & 300 & 1 \\
\hline & 1000 & 2 & 1 & 30 & 300 & 14 \\
\hline
\end{tabular}

Note. Elastic modulus for rock is found to be $8.4 \mathrm{GPa}$ and Poisson's ratio of rock and backfill is 0.29 and 0.33 , respectively. 


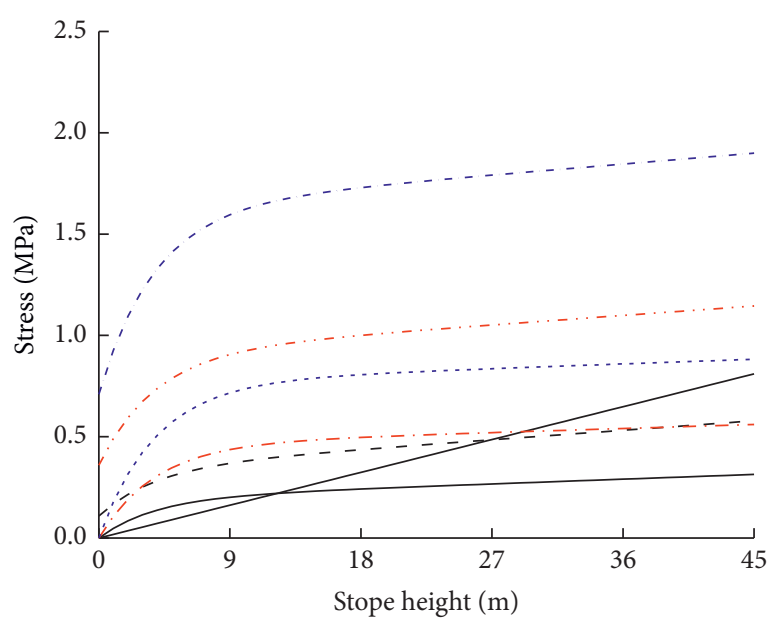

$$
\begin{aligned}
& \text { Self-weight stress of backfill } \\
& \sigma_{\mathrm{v}} \text {, stope depth }=500 \mathrm{~m} \\
& \text {. . } \sigma_{\mathrm{v}} \text {, stope depth }=1000 \mathrm{~m} \\
& \sigma_{\mathrm{v}} \text {, stope depth }=1500 \mathrm{~m} \\
& \text { - - } \sigma_{\mathrm{h}} \text {, stope depth }=500 \mathrm{~m} \\
& \text {. . . } \sigma_{\mathrm{h}} \text {, stope depth }=1000 \mathrm{~m} \\
& \text {... } \sigma_{\mathrm{h}} \text {, stope depth }=1500 \mathrm{~m}
\end{aligned}
$$

FIGURE 14: Stope depth effect on time-dependent stress profile of backfilling.

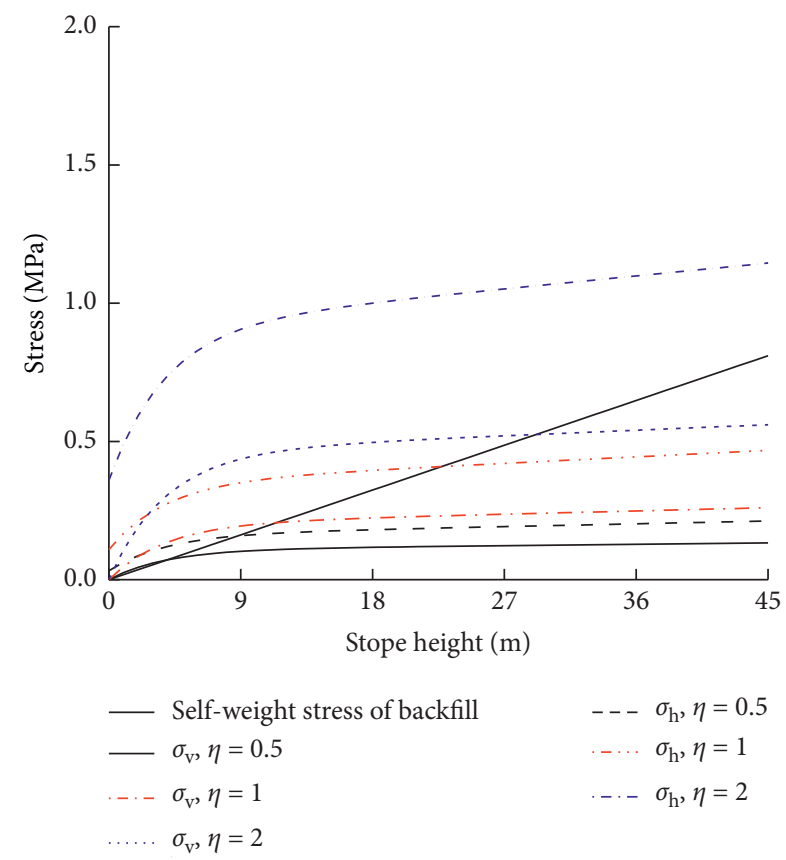

FIGURE 15: Lateral earth pressure effect on time-dependent stress profile of backfilling.

deformation occurs and may then gets back into the stable stage; at this point, the creep deformation rate is relatively small; thus the deformation amount of the nearby rock acting on the backfill is smaller. Thus, the weaker the backfill's stress is under the squeezing capacity of the nearby rock material, the smaller the backfill's internal stress is.

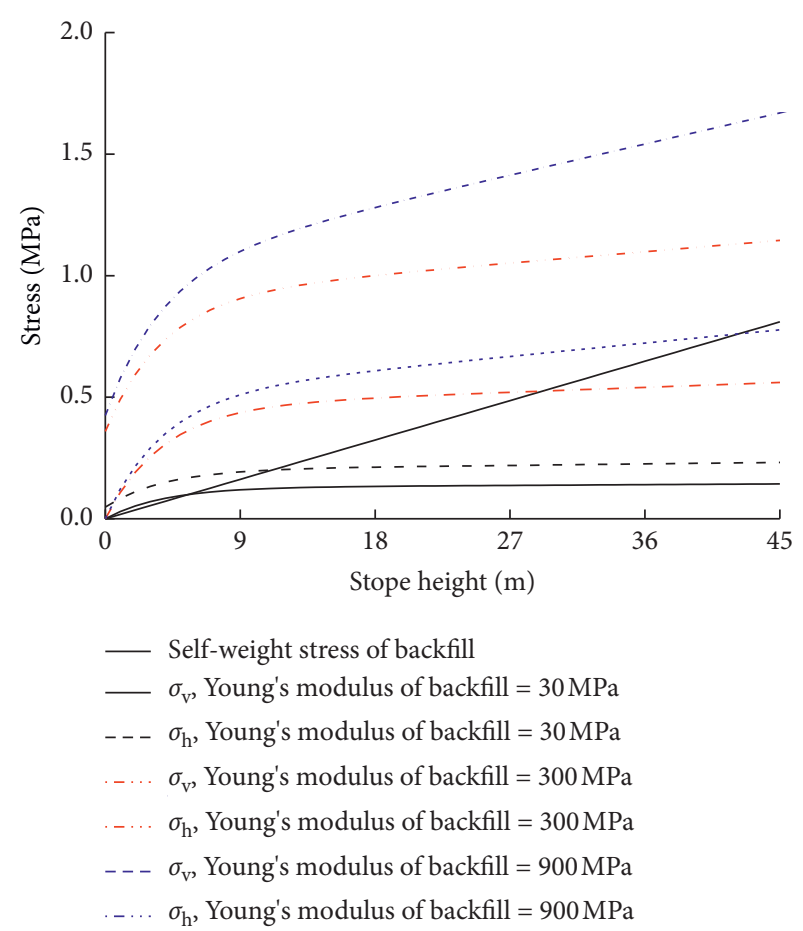

Figure 16: Elastic modulus effect on the time-dependent stress distribution of backfilling.

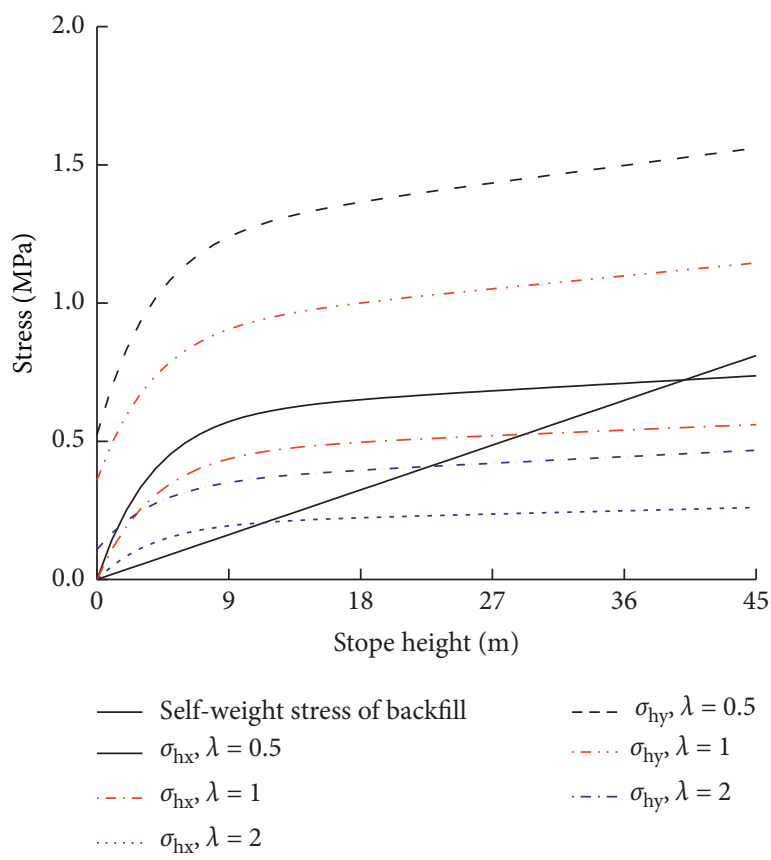

FIGURE 17: Effect of horizontal stress ratio on the time-dependent stress distribution of backfill.

\section{Discussion}

The contact between mine backfilling and nearby rock material is related to drainage, consolidation, and dynamic disturbance conditions of backfill $[10,20]$ and is the result of multifield (THMC) and multifactor coupling. The strength 
of the surrounding rock mass may be weakening under longterm water erosion influenced by backfill with high water and high permeability, thus increasing the deformation tendency of the surrounding rock mass. This process may further squeeze the backfill and result in increase in the stresses in backfill. However, for the cemented paste backfill, the ability of bleeding and permeability is relatively small, so it is reasonable not to consider the effect of water erosion on strength and deformation of the nearby rock material. Besides, a certain water pond on upper sides of the backfilled stope will be formed in early filling stages with regard to the backfill of high bleeding, which will affect the evolution and development of the backfill's internal strength [32]. The upper sides of the backfilled stope may be also affected by the drying and evaporation effects.

The blasting disturbance near the backfilled stope will lead to further deformation of the nearby rock material, which will surge sharply in a short time, causing a sudden increase in stresses in backfill [53]. It is important for the stability analysis of barricades for this sudden increase in stresses in the backfill. In the early stage of backfilling, when the compressive strength of the backfill is small, dynamic disturbance may cause liquefaction of the backfill [54], resulting in sudden changes in the interaction state between mine backfill and the nearby rock material, and how the hardening process changes after liquefaction of the backfill requires further consideration.

\section{Conclusions}

In this study, the spatial and temporal coupling effects of the interaction between the hardening process of backfill and the surrounding rock mass are investigated. The present study proposes a corresponding theoretical model and draws the following main conclusions:

(1) The interaction between mine backfill after filling the stope and the nearby rock material shows three main interaction processes: (i) the support action causes the stress level of the nearby rock material to change, which in turn changes the creep behavior of the nearby rock material; (ii) the squeezing force generated by the nearby rock mass puts the backfill under curing stress; and (iii) the change of shrinkage strain in the hardening process of backfilling affects the deformation of the nearby rock material.

(2) The stress distribution of backfill in circular and high filling stope under the effect of time-dependent deformation of rock is solved. The strength and elastic modulus evolution formula which considers the change of curing time, curing stress, and cement content during curing process of backfill are presented.

(3) When the creeping rock mass enters the second creep stage, the controlling effect of backfill over the creep behavior of the nearby rock material is not obvious. For the nearby rock material with minor creep deformation, the stress distribution inside backfill is mainly dependent on the effect of stress arching. When the stope depth is relatively high and the creep effect of rocks is substantial, the stress distribution in backfill is mainly composed of stress arching and squeezing effect, and the squeezing effect makes the stress distribution in backfill exceed its self-weight stress.

(4) After stope excavation, delay backfilling has a major impact on deformation of the nearby rock material in accordance with the monitoring results of Moser et al. [55].

\section{Data Availability}

The data used to support the findings of this study are included within the article.

\section{Conflicts of Interest}

The authors declare that they have no conflicts of interest regarding the publication of this paper.

\section{Acknowledgments}

The authors would like to sincerely thank the National Natural Science Foundation of China (grant no. 51904055) and the Fundamental Research Funds for the Central Universities of China (grant no. N2001010) for financial support.

\section{References}

[1] X. Li, D. Wang, C. Li, and Z. Liu, "Numerical simulation of surface subsidence and backfill material movement induced by underground mining," Advances in Civil Engineering, vol. 2019, Article ID 2724370, 17 pages, 2019.

[2] I. Ponsot and E. Bernardo, "Self glazed glass ceramic foams from metallurgical slag and recycled glass," Journal of Cleaner Production, vol. 59, pp. 245-250, 2013.

[3] A. U. Shettima, M. W. Hussin, Y. Ahmad, and J. Mirza, "Evaluation of iron ore tailings as replacement for fine aggregate in concrete," Construction and Building Materials, vol. 120 , pp. 72-79, 2016.

[4] A. Rincón, D. Desideri, and E. Bernardo, "Functional glassceramic foams from 'inorganic gel casting' and sintering of glass/slag mixtures," Journal of Cleaner Production, vol. 187, pp. 250-256, 2018.

[5] S. Bea, S. Wilson, K. Mayer, G. Dipple, I. Power, and P. Gamazo, "Reactive transport modeling of natural carbon sequestration in ultramafic mine tailings," Vadose Zone Journal, vol. 11, no. 2, 2012.

[6] T. Deschamps, M. Benzaazoua, B. Bussière, and M. Aubertin, "Laboratory study of surface paste disposal for sulfidic tailings: physical model testing," Minerals Engineering, vol. 24, no. 8, pp. 794-806, 2011.

[7] T. Belem and M. Benzaazoua, "Design and application of underground mine paste backfill technology," Geotechnical and Geological Engineering, vol. 26, no. 2, pp. 147-174, 2007.

[8] D. Kossoff, W. E. Dubbin, M. Alfredsson, S. J. Edwards, M. G. Macklin, and K. A. Hudson-Edwards, "Mine tailings dams: characteristics, failure, environmental impacts, and remediation," Applied Geochemistry, vol. 51, pp. 229-245, 2014. 
[9] S. Yin, Y. Shao, A. Wu, H. Wang, X. Liu, and Y. Wang, "A systematic review of paste technology in metal mines for cleaner production in China," Journal of Cleaner Production, vol. 247, Article ID 119590, 2020.

[10] Q. Zhou, J.-H. Liu, A.-X. Wu, and H.-J. Wang, "Early-age strength property improvement and stability analysis of unclassified tailing paste backfill materials," International Journal of Minerals, Metallurgy and Materials, vol. 27, no. 9, pp. 1191-1202, 2020.

[11] Q. Lei, S. Yannan, and L. Jiangong, "Experimental study on grouting diffusion of gangue solid filling bulk materials," Journal of Mining and Strata Control Engineering, vol. 3, no. 2, Article ID 23015, 2021.

[12] E. M. Jaouhar and L. Li, "Effect of drainage and consolidation on the pore water pressures and total stresses within backfilled stopes and on barricades," Advances in Civil Engineering, vol. 53, no. 4, 2019.

[13] B. Zhang, J. Xin, L. Liu, L. Guo, and K.-I. Song, "An experimental study on the microstructures of cemented paste backfill during its developing process," Advances in Civil Engineering, vol. 2018, pp. 1-10, 2018.

[14] M. Z. Emad, H. Mitri, and C. Kelly, "Dynamic model validation using blast vibration monitoring in mine backfill," International Journal of Rock Mechanics and Mining Sciences, vol. 107, pp. 48-54, 2018.

[15] G. Liu, L. Li, X. Yang, and L. Guo, "Stability analyses of vertically exposed cemented backfill: a revisit to Mitchell's physical model tests," International Journal of Mining Science and Technology, vol. 26, no. 6, pp. 1135-1144, 2016.

[16] Z. Yang, S. Zhai, Q. Gao, and M. Li, "Stability analysis of largescale stope using stage subsequent filling mining method in Sijiaying iron mine," Journal of Rock Mechanics and Geotechnical Engineering, vol. 7, no. 1, pp. 87-94, 2015.

[17] J. B. Seymour, L. A. Martin, M. J. Raffaldi, S. N. Warren, and L. A. Sandbak, "Long-term stability of a $13.7 \times 30.5-\mathrm{m}$ $(45 \times 100-\mathrm{ft})$ undercut span beneath cemented rockfill at the turquoise ridge mine, nevada," Rock Mechanics and Rock Engineering, vol. 52, no. 12, pp. 4907-4923, 2019.

[18] M. J. Raffaldi, J. B. Seymour, J. Richardson, E. Zahl, and M. Board, "Cemented paste backfill geomechanics at a narrow-vein underhand cut-and-fill mine," Rock Mechanics and Rock Engineering, vol. 52, no. 12, pp. 4925-4940, 2019.

[19] X. Zhao, A. Fourie, and C.-c. Qi, "An analytical solution for evaluating the safety of an exposed face in a paste backfill stope incorporating the arching phenomenon," International Journal of Minerals, Metallurgy, and Materials, vol. 26, no. 10, pp. 1206-1216, 2019.

[20] Y.-Y. Tan, X. Yu, D. Elmo, L.-H. Xu, and W.-D. Song, "Experimental study on dynamic mechanical property of cemented tailings backfill under SHPB impact loading," International Journal of Minerals, Metallurgy, and Materials, vol. 26, no. 4, pp. 404-416, 2019.

[21] D. Wu, R.-K. Zhao, C.-W. Xie, and S. Liu, "Effect of curing humidity on performance of cemented paste backfill," International Journal of Minerals, Metallurgy and Materials, vol. 27, no. 8, pp. 1046-1053, 2020.

[22] C. Qi and A. Fourie, "Numerical investigation of the stress distribution in backfilled stopes considering creep behaviour of rock mass," Rock Mechanics and Rock Engineering, vol. 52, no. 9, pp. 1-19, 2019.

[23] Z. Zhou, Y. Zhao, W. Cao, L. Chen, and J. Zhou, "Dynamic response of pillar workings induced by sudden pillar recovery," Rock Mechanics and Rock Engineering, vol. 51, no. 10, pp. 3075-3090, 2018.
[24] Y. Yu, K.-Z. Deng, Y. Luo, S.-E. Chen, and H.-F. Zhuang, “An improved method for long-term stability evaluation of strip mining and pillar design," International Journal of Rock Mechanics and Mining Sciences, vol. 107, pp. 25-30, 2018.

[25] E. Maranini and M. Brignoli, "Creep behaviour of a weak rock: experimental characterization," International Journal of Rock Mechanics and Mining Sciences, vol. 36, no. 1, pp. 127-138, 1999.

[26] J. Zhao, X.-T. Feng, X. Zhang, and C. Yang, "Brittle and ductile creep behavior of Jinping marble under true triaxial stress," Engineering Geology, vol. 258, p. 105157, 2019.

[27] J. Zhao, X.-T. Feng, X. Zhang, C. Yang, and Y. Zhou, “Timedependent behaviour and modeling of Jinping marble under true triaxial compression," International Journal of Rock Mechanics and Mining Sciences, vol. 110, pp. 218-230, 2018.

[28] M. Fahey, M. Helinski, and A. Fourie, "Development of specimen curing procedures that account for the influence of effective stress during curing on the strength of cemented mine backfill," Geotechnical and Geological Engineering, vol. 29, no. 5, pp. 709-723, 2011.

[29] M. Helinski, M. Fahey, and A. Fourie, "Behavior of cemented paste backfill in two mine stopes: measurements and modeling," Journal of Geotechnical and Geoenvironmental Engineering, vol. 137, no. 2, pp. 171-182, 2011.

[30] A. Hasan, A. Karrech, and B. Chareyre, "Evaluating force distributions within virtual uncemented mine backfill using discrete element method," International Journal of Geomechanics, vol. 17, no. 7, Article ID 6016042, 2016.

[31] J. Li, H. Liu, K. Ai, and L. Zhu, "An NMR-based experimental study on the pore structure of the hydration process of mine filling slurry," Advances in Civil Engineering, vol. 2018, pp. 1-12, 2018.

[32] P. Yang, L. Li, and M. Aubertin, "A new solution to assess the required strength of mine backfill with a vertical exposure," International Journal of Geomechanics, vol. 17, no. 10, 2017.

[33] L. Li and M. Aubertin, "An analytical solution for the nonlinear distribution of effective and total stresses in vertical backfilled stopes," Geomechanics and Geoengineering, vol. 5, no. 4, pp. 237-245, 2010.

[34] L. Li, M. Aubertin, and T. Belem, "Formulation of a three dimensional analytical solution to evaluate stresses in backfilled vertical narrow openings," Canadian Geotechnical Journal, vol. 42, no. 6, pp. 1705-1717, 2005.

[35] B. Yan, W. Zhu, C. Hou, and K. Guan, "A three-dimensional analytical solution to the arching effect in inclined backfilled stopes," Geomechanics and Geoengineering, vol. 14, no. 2, pp. 136-147, 2019.

[36] C. H. Ting, N. Sivakugan, W. Read, and S. K. Shukla, “Analytical expression for vertical stress within an inclined mine stope with non-parallel walls," Geotechnical and Geological Engineering, vol. 32, no. 2, pp. 577-586, 2014.

[37] A. Jahanbakhshzadeh, M. Aubertin, and L. Li, "A new analytical solution for the stress state in inclined backfilled mine stopes," Geotechnical and Geological Engineering, vol. 35, no. 3, pp. 1-17, 2017.

[38] P. Rajeev, P. R. Sumanasekera, and N. Sivakugan, "Lateral variation of the vertical stress in underground mine stopes filled with granular backfills," Geotechnical and Geological Engineering, vol. 34, no. 2, pp. 481-492, 2015.

[39] B. Yan and E. Yilmaz, "Analytical solution for stress distribution in cementitious backfills considering stope inclinations," Recep Tayyip Erdogan University Journal of Science and Engineering, vol. 1, no. 2, pp. 26-33, 2020. 
[40] E. Yilmaz, "Stope depth effect on field behaviour and performance of cemented paste backfills," International Journal of Mining, Reclamation and Environment, vol. 32, no. 4, pp. 273-296, 2018.

[41] N. El Mkadmi, M. Aubertin, and L. Li, "Effect of drainage and sequential filling on the behavior of backfill in mine stopes," Canadian Geotechnical Journal, vol. 51, no. 1, pp. 1-15, 2014.

[42] B. D. Thompson, W. F. Bawden, and M. W. Grabinsky, "In situ measurements of cemented paste backfill at the Cayeli Mine," Canadian Geotechnical Journal, vol. 49, no. 7, pp. 755-772, 2012.

[43] J. P. Doherty, A. Hasan, G. H. Suazo, and A. Fourie, "Investigation of some controllable factors that impact the stress state in cemented paste backfill," Canadian Geotechnical Journal, vol. 52, no. 12, pp. 1901-1912, 2015.

[44] S. Yin, Y. Shao, A. Wu, Z. Wang, and L. Yang, "Assessment of expansion and strength properties of sulfidic cemented paste backfill cored from deep underground stopes," Construction and Building Materials, vol. 230, Article ID 116983, 2020.

[45] B. Yan, W. Zhu, C. Hou, Y. Yu, and K. Guan, "Effects of coupled sulphate and temperature on internal strain and strength evolution of cemented paste backfill at early age," Construction and Building Materials, vol. 230, Article ID 116937, 2020.

[46] T. Xu, G. Zhou, M. J. Heap, S. Yang, H. Konietzky, and P. Baud, "The modeling of time-dependent deformation and fracturing of brittle rocks under varying confining and pore pressures," Rock Mechanics and Rock Engineering, vol. 51, no. 10, pp. 3241-3263, 2018.

[47] N. Niroshan, N. Sivakugan, and R. L. Veenstra, "Laboratory study on strength development in cemented paste backfills," Journal of Materials in Civil Engineering, vol. 29, no. 7, Article ID 4017027, 2017.

[48] P. Małkowski, Ł. Ostrowski, and J. Brodny, "Analysis of Young's modulus for Carboniferous sedimentary rocks and its relationship with uniaxial compressive strength using different methods of modulus determination," Journal of Sustainable Mining, vol. 17, no. 3, pp. 145-157, 2018.

[49] L. Li, M. Aubertin, R. Simon, B. Bussière, and T. Belem, "Modeling arching effects in narrow backfilled stopes with FLAC," in Proceedings of the 3rd International Symposium on FLAC \& FLAC 3D Numerical Modelling in Geomechanics, pp. 211-219, Ontario, Canada, October 2003.

[50] P. Rajeev, P. R. Sumanasekera, and N. Sivakugan, "Average vertical stresses in underground mine stopes filled with granular backfills," Geotechnical and Geological Engineering, vol. 34, no. 6, pp. 2053-2061, 2016.

[51] L. Li and M. Aubertin, "Limit equilibrium analysis for the design of backfilled stope barricades made of waste rock," Canadian Geotechnical Journal, vol. 48, no. 11, pp. 1713-1728, 2011.

[52] R. L. Handy, "The arch in soil arching," Journal of Geotechnical Engineering, vol. 111, no. 3, pp. 302-318, 1985.

[53] G. Suazo, A. Fourie, and J. Doherty, "Experimental investigation of propagation and transmission of compressional stress waves in cemented paste backfill," Journal of Geotechnical and Geoenvironmental Engineering, vol. 143, no. 3, 2016.

[54] M. Shahsavari, R. Moghaddam, M. Jafari, and M. Grabinsky, "Preliminary investigation of liquefaction potential of cemented paste backfill under dynamic loading using a twodimensional, time-domain ground response analysis," in
Proceedings of the 12th International Symposium on Mining with Backfill, Mount Isa, Australia, February 2017.

[55] A. Moser, F. Wallner, H. Wagner, and T. Ladinig, "An experimental study to investigate the interaction of backfill and rock mass," in Ground Support 2016, E. Nordlund, Ed., Lulea University of Technology, Luleå, Sweden, 2016. 